\title{
Tropical biases in CMIP5 multi-model ensemble: The excessive equatorial Pacific cold tongue and double ITCZ problems
}

\author{
Gen Li* \\ State Key Laboratory of Tropical Oceanography, South China Sea Institute of \\ Oceanology, Chinese Academy of Sciences, Guangzhou, Guangdong, China; \\ International Pacific Research Center, University of Hawaii at Monoa, Honolulu, \\ Hawaii, USA; Scripps Institution of Oceanography, University of California at San \\ Diego, La Jolla, California, USA

\section{Shang-Ping Xie} \\ Scripps Institution of Oceanography, University of California at San Diego, La Jolla, \\ California, USA; International Pacific Research Center, University of Hawaii at \\ Monoa, Honolulu, Hawaii, USA; Physical Oceanography Laboratory, Ocean \\ University of China, Qingdao, Shandong, China
}

*Corresponding author: Gen Li, State Key Laboratory of Tropical Oceanography, South China Sea Institute of Oceanology, 164 West Xingang Road, Guangzhou 510301, China.Email: ligen@hawaii.edu 


\section{ABSTRACT}

Errors of coupled general circulation models (CGCMs) limit their utility for climate prediction and projection. Origins of and feedback for tropical biases are investigated in the historical climate simulations of eighteen CGCMs from the Coupled Model Intercomparison Project phase 5 (CMIP5), together with the available Atmospheric Model Intercomparison Project (AMIP) simulations. Based on an intermodel Empirical Orthogonal Function (EOF) analysis of tropical Pacific precipitation, the excessive equatorial Pacific cold tongue and double intertropical convergence zone (ITCZ) stand out as the most prominent errors of the current generation of CGCMs. The comparison of CMIP-AMIP pairs enables us to identify whether a given type of errors originates from atmospheric models. The equatorial Pacific cold tongue bias is associated with deficient precipitation and surface easterly wind bias in the western half of the basin in CGCMs, but these errors are absent in atmosphere-only models, indicating that the errors arise from the interaction with the ocean via Bjerknes feedback. For the double ITCZ problem, excessive precipitation south of the equator correlates well with excessive downward solar radiation in the Southern Hemisphere ( $\mathrm{SH}$ ) midlatitudes, an error traced back to atmospheric model simulations of cloud during austral spring and summer. This extratropical forcing of the ITCZ displacements is mediated by tropical ocean-atmosphere interaction, and is consistent with recent studies of ocean-atmospheric energy transport balance.

\section{Introduction}

The ocean-atmosphere system displays large zonal and meridional variations over the tropical Pacific. The equatorial easterly wind stress generates upwelling of cold water, resulting in the equatorial Pacific cold tongue that suppresses atmospheric convection/precipitation. Positive ocean-atmosphere feedback proposed by Bjerkens (1969) is important for the equatorial cold tongue. The tropical Pacific climatology also exhibits pronounced north-south asymmetry with intense precipitation and warm sea surface temperature (SST) in the Northern Hemisphere (NH) intertropical convergence zone (ITCZ). Ocean-atmosphere interactions, such as wind-evaporationSST (WES) (Xie and Philander 1994) and stratus-SST (Philander et al. 1996) feedbacks, are important for maintaining the northward displaced ITCZ. 
Generations of coupled general circulation models (CGCMs) used for climate predictions and projections suffer from large errors in simulating the equatorial Pacific cold tongue and ITCZ for nearly two decades (Mechoso et al. 1995; Yu and Mechoso 1999; Davey et al. 2002; Meehl et al. 2005; Dai 2006; Lin 2007; Randall et al. 2007; de Szoeke and Xie 2008). Most CGCMs suffer from a cool SST error and excessive westward extension of the equatorial Pacific cold tongue in comparison to observations. In a recent heat budget analysis, Zheng et al. (2012) examined 15 Coupled Model Intercomparison Project 3 (CMIP3) coupled simulations and attributed the equatorial Pacific cold tongue error to too strong zonal currents as well as excessive oceanic upwelling and the vertical temperature gradient associated with overly strong surface zonal winds. However, whether the surface wind errors in the coupled models are due to biases of the atmospheric models or come from oceanatmosphere feedback is still unclear.

Most of the state-of-the-art CGCMs suffer from the so-called double ITCZ problem (Lin 2007; Hirota et al. 2011; Hwang and Frierson 2013). Excessive precipitation in the Southern Hemisphere ( $\mathrm{SH}$ ) corresponds to a SH counterpart to the strong $\mathrm{NH}$ ITCZ, despite decades of hard work by modeling centers, for example, by modifying the convection parameterization scheme (Hess et al. 1993; Frey et al. 1997; Zhang and Wang 2006; Song and Zhang 2009; Chikira 2010; Zhang and Song 2010), changing the surface wind stress formulation (Luo et al. 2005), or increasing the model resolution (Mechoso 2006). The cause of the double ITCZ problem in CGCMs is complex. Many studies attribute this error to tropical origins, including a poor representation of ocean-atmosphere feedbacks (Lin 2007), unrealistic winds in the eastern Pacific warm pool due to the complex Central American orography along with improper southern tropical low-level clouds (de Szoeke and Xie 2008), unrealistic SST threshold leading to the onset of deep convection (Belluci et al. 2010), improper entrainment effect (Hirota et al. 2011), or/and unrealistic alongshore winds at the Chile and Peru associated with the orography of the Andean Cordillera (Zheng et al. 2011).

The recent work of Hwang and Frierson (2013) argues that cloud biases outside the tropics contribute to the double ITCZ problem, consistent with the theoretical prediction that the tropical precipitation shifts towards the hemisphere receiving extra heat from ocean or sun (Kang et al. 2008, 2009). Although Hwang and Frierson's (2013) work reveals a robust statistical relationship between the tropical double ITCZ 
problem and extratropical cloud biases in CGCMs, many issues remain unresolved. For example, whether the extratropical cloud biases are of atmospheric origin or due to ocean-atmosphere feedback is still unclear. Once the interhemispheric asymmetry biases in the tropics are initiated by the extratropical cloud biases, how do tropical ocean-atmosphere feedbacks amplify and maintain them? While previous studies focus separately on the Pacific (e.g. de Szoeke and Xie 2008) and Atlantic (e.g. Breugem et al. 2006; Richter and Xie 2008) double ITCZ biases, it is unclear whether the basin-scale precipitation errors are limited to individual tropical basins or coherently connected to global biases Hwang and Frierson (2013) identified. There are physical reasons for developing global-scale errors in the tropics. For example, tropospheric temperature is nearly uniform in space within the tropics due to fast equatorial waves (Sobel and Bretherton 2000; Sobel et al. 2002; Johnson and Xie 2010). In addition, the seasonal cycle of extratropical cloud radiative forcing and tropical double ITCZ biases has not been studied.

Forced with observed SST, Atmospheric Model Intercomparison Project (AMIP) simulations can be used to isolate biases in atmospheric models and relate them to those of coupled models. By comparing pairs of CMIP and AMIP runs, Li and Xie (2012) show that tropical mean SST biases in CGCMs originate from cloud biases in atmospheric models. The present study adopts this method to isolate the sources of major model biases in the tropical Pacific, i.e. in the cold tongue and ITCZ.

The present study examines the nature and sources of tropical Pacific precipitation pattern biases in 18 CMIP5 CGCMs. We show that precipitation errors in the equatorial Pacific cold tongue and ITCZ remain large in CMIP5 climate models. By comparing pairs of CMIP and AMIP simulations, we examine to what extent these errors can be traced back to biases of atmospheric models. Regarding the equatorial Pacific cold tongue, our study reveals that the deficient precipitation and easterly wind biases are absent in AMIP simulations and result from the interaction with $\mathrm{SST} /$ thermocline. We find that errors of excessive shortwave radiation due to insufficient cloud radiative forcing in the $\mathrm{SH}$ midlatitudes originate from atmosphereonly models. The double ITCZ biases are of the global scale and most pronounced during the SH rainy season to balance the interhemispheric heating asymmetry. In particular, WES feedback mediates the extratropical cloud radiative forcing to influence the ITCZ. 
The CMIP5 CGCMs are becoming widely used for global climate predictions and projections (Taylor et al. 2012). Large errors in simulation of the Pacific cold tongue and ITCZ mean limit the skills of CGCMs in simulating El Niño-Southern Oscillation (ENSO) and its teleconnections (Latif et al. 2001; Guilyardi 2006; AchutaRao and Sperber 2006; Wittenberg et al. 2006; Misra et al. 2008; Ham and Kug 2012). Our study highlights physical processes for the two types of model biases, and will help reduce these errors in future model development/improvement efforts by the modeling community.

The rest of this paper is organized as follows. Section 2 describes the models and datasets used in this study. Section 3 isolates the equatorial cold tongue and double ITCZ problems in tropical Pacific precipitation pattern in CMIP5 multi-model ensemble by using an inter-model Empirical Orthogonal Function (EOF) analysis (Li and Xie 2012). Sections 4 and 5 further investigate the equatorial Pacific cold tongue and double ITCZ biases, respectively. Section 6 is a summary with discussion.

\section{Models and datasets}

We examine the 30-yr (1970-99) climate of the historical runs from the World Climate Research Program (WCRP) CMIP5 multi-model ensemble (Taylor et al. 2012), together with the available AMIP simulations. Monthly mean outputs from 18 CMIP5 CGCMs are used, including precipitation, surface winds, SST, latent heat flux (LHF), sensible heat flux (SHF), and shortwave and longwave radiation fluxes at the sea surface; ocean temperature; shortwave and outgoing longwave radiation in all sky, and outgoing shortwave/longwave radiation in clear sky at the top of atmosphere (TOA). Table 1 shows the model names, modeling centers, and whether the AMIP simulations are available. Further information on individual models is available at http://www-pcmdi.llnl.gov/ (Taylor et al. 2012). Here, we only use one member ('rli1p1') run for each model.

For comparison, we also examine both the observed and reanalyzed (assimilated) datasets (for simplicity referred to as "observations"). Specifically, the precipitation climatology is obtained from the Global Precipitation Climatology Project (GPCP; Adler et al. 2003) and CPC Merged Analysis of Precipitation (CMAP; Xie and Arkin 1997) datasets for 1979-2008. The results from the two precipitation datasets are very similar, and only the results from the GPCP precipitation dataset are shown except in Fig. 1. The SST climatology is gained from the NOAA Optimal Interpolation Sea 
Surface Temperature (OISST) analyses (Reynolds et al. 2002) for 1982-2011. The surface wind observations are the climatology from August 1999 through August 2009 based on monthly QuikSCAT satellite scatterometer retrievals (http://www.remss.com) and from the National Center for Atmospheric ResearchNational Centers for Environmental Prediction (NCEP-NCAR) reanalysis project for 1970-1999 (Kalnay et al. 1996). Although the two surface wind products cover different time periods, the climatology is very similar. Only the results from the QuikSCAT scatterometer retrievals are shown, unless otherwise specified. In addition, the ocean temperature from the Simple Ocean Data Assimilation (SODA) reanalysis (Carton and Giese 2008) from 1970-1999 is used. Finally, the observed energy fluxes at the TOA for 2001-2011 are from Clouds and the Earth's Radiant Energy System (CERES) Energy Balance and Filled (EBAF) dataset (Wielicki et al. 1996). Here, we do not use observed surface heat flux datasets because of large uncertainties (Yu and Weller 2007; Zheng et al. 2012). All model outputs and observational datasets are interpolated to a uniform $2^{\circ} \times 2^{\circ}$ horizontal grid, unless otherwise specified.

\section{The leading bias modes}

Figs. 1a and $1 \mathrm{~b}$ show the zonally and annually averaged precipitation and SST in the tropical Pacific $\left(120^{\circ} \mathrm{E}-80^{\circ} \mathrm{W}\right)$ for observations (black lines) and $18 \mathrm{CMIP5}$ CGCMs (colored lines), respectively. Here, we focus on the model biases in tropical Pacific precipitation and SST distributions by normalizing with their respective tropical means $\left(20^{\circ} \mathrm{S}-20^{\circ} \mathrm{N}\right)$ for observations and each model. Although the CGCMs qualitatively simulate the meridional profiles of annual mean precipitation and SST in the tropical Pacific, there are two important types of biases to note. First, most CMIP5 CGCMs still suffer from the insufficient precipitation and cool SST biases on the equator, i.e. an excessive equatorial Pacific cold tongue as in the pervious generations of CGCMs. Second, while observations show a strong interhemispheric asymmetry of precipitation and SST with one single NH ITCZ, most CMIP5 CGCMs produce excessive precipitation in the $4^{\circ}-10^{\circ} \mathrm{S}$ band and deficient precipitation in the $4^{\circ}-8^{\circ} \mathrm{N}$ band in the tropical Pacific. This is the well-known double ITCZ problem. These two types of biases in precipitation are not significant in the AMIP simulations (Fig. 1c).

Although these results are similar to the findings in earlier studies (e.g. Lin 2007), the meridional profiles normalized by the tropical means in Fig. 1 exclude the effects 
of the tropical mean precipitation and SST offset biases in the CGCMs (Li and Xie 2012), and highlight the model biases in spatial pattern. For instance, while the absolute precipitation values on the equator in CGCMs are symmetrically distributed around observations within a range of about $2 \mathrm{~mm}$ /day (Fig. $2 \mathrm{~b}$ of de Szoeke and Xie 2008), equatorial precipitation in Fig. 1a is systematically lower than observations by excluding the systematical overestimation of tropical mean precipitation in models relative to observations. This tropical mean error may be due to observational uncertainties (Trenberth et al. 2009; Stephens et al. 2012) or biases of deep convection schemes in the atmospheric models (Lin 2007). Similarly, while the absolute model SSTs in the tropical South Pacific are symmetrically distributed around observations within a range of about $2^{\circ} \mathrm{C}$ (Fig. 2a of de Szoeke and Xie 2008), SSTs in $4^{\circ}-10^{\circ} \mathrm{S}$ in Fig. $1 \mathrm{~b}$ are systematically higher than observations by excluding the tropical mean offset, which may be due to biases in atmospheric model representation of cloud cover for the tropics ( $\mathrm{Li}$ and Xie 2012). This reduced SST asymmetry explains why the model precipitation is systematically overestimated in the tropical South Pacific. In fact, the onset of tropical deep convection in CGCMs is not controlled solely by local SST itself, but depends on the difference between the local and tropical mean SSTs (Xie et al. 2010; Johnson and Xie 2010), due to the fact that the tropical free-tropospheric temperature is more uniform in space than SST, flattened by fast communications by equatorial waves (Sobel et al. 2002).

To isolate the dominant patterns of tropical Pacific precipitation biases, we carry out an inter-model EOF analysis. Instead of temporal variance in conventional EOF analysis, our EOF analysis maximizes the variance of precipitation differences among CMIP5 models. First, the annual mean precipitation for each CMIP5 CGCM is normalized by their respective tropical mean values. Then, the inter-model EOF analysis is applied to the zonally averaged precipitation deviations from the multimodel ensemble mean (MME) over the tropical Pacific. Fig. 2 shows the regressed patterns of precipitation, SST, and surface winds onto the first two principal components (PCs) as well as the PCs. When the inter-model EOF analysis is applied to two-dimensional $(x-y)$ normalized precipitation anomalies, the leading EOF modes are very similar (figure not shown).

\section{a) $E O F 1$}


The first inter-model EOF mode (EOF1, Fig. 2a), explaining 57.6\% of total intermodel variability, captures the deficient precipitation and cool SST in the equatorial Pacific, flanked by the excessive precipitation and warm SST on the flanks. Spatial correlation between precipitation and SST patterns is 0.56 , illustrating a strong control of SST pattern on annual mean tropical Pacific precipitation, consistent with the previous studies (Xie et al. 2010; Ma and Xie 2013). In the previous study (Li and Xie 2012), we applied the inter-model EOF analysis to annual mean SST climatology (non-normalized) over tropical oceans in the CMIP3 multi-model ensemble. While the first mode characterizes the tropical mean SST offset bias, the second mode reflects the equatorial cold tongue SST bias, similar to Fig. 2a that normalizes with the tropical mean to isolate pattern biases. The easterly wind anomalies are found in the western half of the equatorial Pacific, acting to enhance the equatorial eastern Pacific SST cooling by shoaling (deepening) the ocean thermocline in the east (west), suggestive of Bjerknes feedback in the excessive equatorial Pacific cold tongue.

Models with high PC1 values would have a large precipitation deficit in the equatorial Pacific clod tongue. Here, we choose three models of highest PC1 values as the strong equatorial cold tongue (EQ ${ }^{-}$) models (M4, M15, and M16), and three of lowest PC1 values as the weak equatorial cold tongue $\left(\mathrm{EQ}^{+}\right)$models (M1, M8, and $\mathrm{M} 9)$. Indeed, $\mathrm{EQ}^{-}$models have deficient precipitation on the equator, with excessive precipitation on the sides (Fig. 3a).

\section{b) $E O F 2$}

The second inter-model EOF mode (EOF2, Fig. 2b), explaining 20.1\% of total inter-model variability, exhibits a latitudinal asymmetrical precipitation distribution with excessive precipitation in the $\mathrm{SH}$ tropics and deficient precipitation in $4^{\circ}-8^{\circ} \mathrm{N}$. The pattern is most pronounced in the central and eastern Pacific and Atlantic. The anomalous cross-equatorial northerly surface winds occur in all three ocean basins, transporting anomalous moisture southward with the excessive precipitation in the $\mathrm{SH}$ tropics. Thus, EOF2 represents the double ITCZ problem. When the inter-model EOF analysis is applied to annual mean SST climatology (normalized) over tropical oceans in the CMIP5 multi-model ensemble, the second mode captures an interhemispheric asymmetrical SST bias (i.e. the double ITCZ bias; figure not shown), similar to Fig. $2 \mathrm{~b}$. This suggests a strong link between tropical precipitation and SST patterns. We 
choose three models of highest PC2 values as the strong double ITCZ problem (NS $\left.{ }^{-}\right)$ models (M8, M11, and M18), and three of lowest PC2 values as the weak or non double ITCZ problem (NS ${ }^{+}$) models (M4, M10, and M14). Indeed, $\mathrm{NS}^{-}$models exhibits excessive Pacific precipitation in the SH (Fig. 3a), indicative of an interhemispheric asymmetry bias.

Although EOF2 is only derived from the tropical Pacific precipitation biases, the anomalous interhemispheric asymmetry in precipitation and cross-equatorial northerly surface winds are not limited to the tropical Pacific, but are also coherent in most of tropical regions, especially in the Atlantic. This implies that the double ITCZ biases represented by EOF2 are of the global scale. Indeed, the globally averaged meridional precipitation in the $\mathrm{NS}^{-}$models is nearly symmetric about the equator, suggestive of the global nature of the double ITCZ biases (Fig. 3b).

Table 2 shows the inter-model relationship between the global and sectoral averaged tropical precipitation asymmetry indices in observations and 18 CMIP5 models. Three sectors are considered: the Pacific $\left(120^{\circ} \mathrm{E}-80^{\circ} \mathrm{W}\right)$, South AmericaAtlantic $\left(80^{\circ} \mathrm{W}-0\right)$, and Africa-Indian Ocean $\left(0-90^{\circ} \mathrm{E}\right)$. The tropical precipitation asymmetry indices are the precipitation difference between the $\mathrm{NH}$ (equator to $20^{\circ} \mathrm{N}$ ) and $\mathrm{SH}$ (equator to $20^{\circ} \mathrm{S}$ ) tropics normalized by the respective tropical means. The tropical precipitation asymmetry indices in the three regions are closely related to the global precipitation asymmetry index, with the inter-model correlations of $0.88,0.79$, and 0.63 , respectively. Similarly, the sectorial cross-equatorial surface winds in the three ocean basins are highly correlated with the global cross-equatorial surface winds (Table 3), with $r=0.92,0.82$, and 0.79 , respectively. These results indicate that the interhemispheric asymmetry biases in tropical precipitation captured by EOF2 are global.

\section{Equatorial Pacific cold tongue bias}

Fig. 4a shows the scatter diagram for precipitation in the equatorial Pacific $\left(140^{\circ} \mathrm{E}-\right.$ $100^{\circ} \mathrm{W}, 5^{\circ} \mathrm{S}-5^{\circ} \mathrm{N}$ ) between CMIP5 CGCMs and the corresponding AMIP simulations. While almost all AMIP simulations have positive precipitation biases relative to observations, most of their coupled simulations have negative precipitation biases. Most models except M8 (a model with a extremely warm SST bias in the equatorial Pacific cold tongue; Lin 2007) experience less equatorial Pacific precipitation in 
CMIP than in AMIP simulations. The inter-model correlation of the equatorial Pacific precipitation between the CMIP and AMIP simulations is only 0.35 (not statistically significant), suggesting that the insufficient precipitation in the equatorial Pacific cold tongue is not an intrinsic error of atmospheric models but rather arises from the interaction with ocean. Indeed, models with a stronger (weaker) decrease in CMIPAMIP tend to have less (more) precipitation in the equatorial Pacific (Fig. 4b), with a high inter-model correlation of 0.91 . In addition, the inter-model correlation between the precipitation and SST in the equatorial Pacific among observations and 18 CMIP5 CGCMs is 0.80 (Fig. 4c), confirming the interaction with the SST biases.

Figs. 5a and 5b compare the Pacific precipitation and SST along the equator among observations and $\mathrm{EQ}^{-}$models, respectively. All the $\mathrm{EQ}^{-}$models represent the negative precipitation and cool SST biases compared to observations, suggestive of an excessive equatorial Pacific cold tongue. While the zonal equatorial winds in the EQ models agree well with observations in the eastern half of the equatorial Pacific, they feature pronounced easterly wind biases in the western basin (Fig. 5c). This relationship between precipitation, SST, and zonal wind is suggestive of Bjerknes feedback. By contrast, the AMIP simulations have excessive precipitation in the equatorial Pacific, particularly in the western equatorial Pacific (Fig. 5a). Both the insufficient precipitation and easterly wind biases are absent in the AMIP runs (Figs. $5 \mathrm{a}$ and $5 \mathrm{c}$ ), indicative of the interaction with the ocean. All the $\mathrm{EQ}^{-}$models have too shallow a thermocline (represented by the $20{ }^{\circ} \mathrm{C}$ isotherm) in the eastern equatorial Pacific (Fig. 5d) that helps bring cold water to the surface, consistent with excessive easterly wind errors in the western basin. While we focus on three models of strong $\mathrm{EQ}^{-}$biases, the shallow thermocline biases in the eastern equatorial Pacific occur in most of other models (figure not shown), albeit weaker in magnitude.

\section{Double ITCZ bias}

\section{a) Cloud radiative forcing effect}

Fig. 6 examines the relationship of the global-zonally averaged meridional surface winds on the equator with the PC2 values and global tropical asymmetry indices (0$20^{\circ} \mathrm{N}$ minus $0-20^{\circ} \mathrm{S}$ ) in precipitation and SST among CMIP5 CGCMs. The crossequatorial surface wind anomalies transport anomalous moisture southward, resulting in a global double ITCZ problem. Indeed, models with stronger southward cross- 
equatorial surface wind anomalies tend to have larger PC2 values and weaker interhemispheric tropical asymmetry in precipitation and SST, with the inter-model correlations of $-0.81,0.88$, and 0.76 , respectively. Thus, models with stronger southward cross-equatorial surface wind biases tend to suffer from a more severe double ITCZ problem.

Fig. 6 is consistent with a previous study (Hwang and Frierson 2013). Anomalous southward cross-equatorial surface winds are associated with an anomalous northward cross-equatorial energy transport by the Hadley cell. For annual mean, an energy perturbation into the atmosphere from the sea surface/TOA at one given region will be balanced by an anomalous atmospheric energy transport (e.g. Zelinka and Hartmann 2012; Donohoe and Battish 2012). If more energy enters into the atmosphere at the surface and TOA in the $\mathrm{SH}$ than in the $\mathrm{NH}$, the northward crossequatorial energy transport by the Hadley cell with a southward displacement of the ITCZ is needed to balance the interhemispheric energy transport (Kang et al. 2008, 2009). Thus, exploring the interhemispheric asymmetry biases of atmospheric energy terms at the surface and TOA helps understand the origins of the anomalous crossequatorial energy and moisture transports as well as the double ITCZ problem in CGCMs (Hwang and Frierson 2013).

Fig. 7a shows the zonal mean distributions of net surface heat flux composited from the $\mathrm{NS}^{-}$and $\mathrm{NS}^{+}$models. There is no large difference in net surface heat flux between the models. We then focus on the net downward cloud radiative forcing shortwave (CRF-sw) and longwave (CRF-lw) fluxes at the TOA. Fig. 8 summarizes the interhemispheric asymmetry of these quantities, and their extratropical and tropical contributions. Interhemispheric difference in extratropical CRF-sw (Fig. 8b) is associated with insufficient CRF-sw in the $\mathrm{SH}$ midlatitudes $\left(30^{\circ}-60^{\circ} \mathrm{S}\right.$; Fig. $7 \mathrm{~b}$; Hwang and Frierson 2013). It is worth noting that the SH midlatitude cloud bias is already present in atmosphere-only models (Fig. 7b), but has little effect on CRF-lw. In the tropics, the interhemispheric difference in CRF-sw exhibits an opposing change from atmospheric to coupled simulations. An increase in convective cloud due to a southern ITCZ bias in CMIP reduces shortwave radiation south of the equator. This CRF-sw bias is a negative feedback for the ITCZ bias but largely offset by an opposing change in CRF-lw bias from AMIP to CMIP (Fig. 8c). The increase in 
convective cloud south of the equator in CMIP reduces outgoing longwave radiation (OLR) there.

Fig. 9a shows the relationship in interhemispheric asymmetry between the midlatitude CRF-sw and tropical precipitation among 18 CMIP5 CGCMs. Models with a weak interhemispheric asymmetry in midlatitude CRF-sw tend to have a weak interhemispheric asymmetry in tropical precipitation and suffer from a severe double ITCZ problem. The inter-model correlation is 0.78 , consistent with the results from the $\mathrm{NS}^{-}$composites in Fig. 8. Similarly, there is a strong correlation $(r=0.92)$ in interhemispheric asymmetry among models between tropical CRF-lw and precipitation (Fig. 9b), suggestive of a positive feedback. Interestingly, the correlation between the interhemispheric asymmetry in tropical CRF-sw and precipitation is low among CMIP5 climate models (figure not shown; $r=-0.12$ ). This might be due to two opposing CRF-sw feedback regimes in the tropical southeastern Pacific and Atlantic. At the beginning, an increased SST in these regions breaks up the low-cloud deck and increases the downward CRF-sw (Philander et al. 1996; Ma et al. 1996; Yu and Mechoso 1999). When a double ITCZ develops, however, a further increase in SST will result in increased convection/high-cloud and reduce the downward CRF-sw.

Our analysis suggests a possible mechanism for the double ITCZ problem. The excessive downward shortwave associated with too low CRF-sw in AMIP simulations warms the SH midlatitudes. The interhemispheric asymmetry of extratropical heating is then spread into the tropics, inducing an anomalous Hadley cell with the northward energy transport in the upper branch and southward moisture transport in the lower branch across the equator in order to balance the interhemispheric energy deficit.

\section{b) Tropical ocean-atmosphere feedback}

Although there is no large difference in the interhemispheric asymmetry in net surface heat flux between the $\mathrm{NS}^{-}$and $\mathrm{NS}^{+}$models, this does not necessarily mean that ocean-atmosphere interactions via sea surface flux are not important for developing the double ITCZ biases. In fact, surface heat flux includes distinct and opposing components of atmospheric forcing and ocean response. They adjust to a new equilibrium in response to a perturbation such as an excessive heating in the $\mathrm{SH}$ midlatitudes. As illustrated above, while the excessive heating in the SH midlatitudes is spread into the SH tropics by baroclinic eddies (Hwang and Frierson 2013), it 
forces anomalous southward cross-equatorial surface winds. Further, the reduced southeasterly (intensified northeasterly) trade winds in the tropics could help warm (cool) SST south (north) of the equator, resulting in a reduced interhemispheric asymmetry in tropical SST/precipitation. Indeed, coupled ocean-atmospheric patterns in Fig. 2b are suggestive of WES feedback over the eastern Pacific and Atlantic (Xie and Philander 1994; Xie 1996), a mechanism that could connect the midlatitude cloud bias to the double ITCZ problem within the tropics.

Fig. 10 shows the tropical NH minus SH differences in precipitation, SST, and zonal wind, together with the cross-equatorial meridional wind over the tropical eastern Pacific $\left(140^{\circ} \mathrm{W}-80^{\circ} \mathrm{W}, 10^{\circ} \mathrm{S}-10^{\circ} \mathrm{N}\right)$ and Atlantic $\left(40^{\circ} \mathrm{W}-0,10^{\circ} \mathrm{S}-10^{\circ} \mathrm{N}\right)$ for observations, and CMIP and AMIP simulations of the $\mathrm{NS}^{-}$models. Compared to observations, the $\mathrm{NS}^{-}$coupled models develop too weak a NH-SH asymmetry in tropical precipitation and SST (Fig. 10a). Unlike the coupled simulations, the tropical precipitation asymmetry is quite realistic in the AMIP simulations with prescribed SST (Fig. 11a). The tropical precipitation asymmetry in the coupled runs is highly correlated with that in the CMIP minus AMIP runs (Fig. 11b) as well as with the tropical SST asymmetry (Fig. 11c), with the inter-model correlations of 0.95 and 0.90 , respectively. Compared to AMIP, the reduced NH-SH SST/precipitation asymmetry is associated with weakened NH-SH asymmetry in zonal wind (Fig. 10b) and crossequatorial wind (Fig. 10c) in coupled runs, suggestive of WES feedback in the tropics.

Surface LHF is calculated based on a bulk formula (Yu and Weller 2007; Li et al. 2011a, 2011b):

$$
L H F=L \rho_{a} C_{E} W\left[q_{s}(T)-R H q_{s}(T-\Delta T)\right],
$$

where $L$ is the latent heat of evaporation, $\rho_{a}$ surface air density, $C_{E}$ the transfer coefficient, $W$ surface wind speed, $R H$ surface relative humidity, $T$ and $\Delta T$ are the SST and the difference from surface air temperature, $q_{s}$ is the saturation humidity following the Clausius-Clapeyron (CC) equation, $q_{s}(T-\Delta T)=q_{s}(T) e^{-\alpha \Delta T}$, $\alpha=L /\left(R_{v} T^{2}\right) \sim 0.06 K^{-1}$, and $R_{v}$ the gas constant for water vapor. Surface LHF can be decomposed into a SST response term $L H F_{O}^{\prime}=\alpha \overline{L H F} T^{\prime}$, and a residual $L H F_{A}^{\prime}=L H F^{\prime}-L H F_{O}^{\prime}$ that represents atmospheric forcing due mostly to changes in wind speed, $R H$, and $\Delta T$. Here the overbar and prime denote the mean and perturbation, respectively. In particular, the atmospheric forcing due to changes in wind speed (WES term) is obtained by linearizing (1) into $L H F_{W}^{\prime}=\overline{L H F} \frac{W^{\prime}}{\bar{W}}$ (Du and 
Xie 2008). In general, the wind speed forcing (WES term) and SST response term interact in the tropics. For example, with an increase in wind speed, the ocean would respond by lowering SST to oppose the increase in LHF. For climatology, the mixedlayer heat budget can be expressed as follows (Xie et al. 2010):

$$
D_{O}^{\prime}+Q_{r a d}^{\prime}-\left(L H F_{O}^{\prime}+L H F_{W}^{\prime}+Q_{r e s}^{\prime}\right)=0,
$$

where $D_{O}^{\prime}$ represents ocean heat transport change due to three-dimensional advection and mixing; $Q_{\text {rad }}^{\prime}$ is net surface radiation change; $Q_{r e s}^{\prime}$ is a residual that represents the effect of surface SHF and atmospheric forcing (except WES term) of surface LHF. In equilibrium, the ocean heat transport effect can be evaluated from the net surface heat flux. Accordingly, by comparing the wind forcing and SST response term in CMIP minus AMIP simulations, we examine to what extent the tropical meridional asymmetry biases in SST/precipitation can be explained by WES feedback.

Fig. 12 shows the tropical NH minus SH differences in net surface radiation, SST response and WES terms of surface LHF, and ocean heat transport over the tropical eastern Pacific and Atlantic in CMIP minus AMIP simulations of the $\mathrm{NS}^{-}$models. The WES effect is a major component of the surface heat budget for the tropical SST bias of north-south asymmetry. The net surface radiation is a negative feedback for the tropical meridional asymmetry bias in SST because a southern ITCZ in coupled models increases convective cloud and reduces downward shortwave radiation south of the equator. However, the contribution of net surface radiation is relatively small and roughly canceled with that of ocean heat transport. Thus, while the NH-SH asymmetry bias ultimately originates from the SH midlatitude clouds in atmosphereonly models, WES feedback is important for the coupled adjustment within the tropics.

\section{c) Seasonal cycle errors}

Fig. 13a shows the seasonal cycle of the CRF-sw biases in the $\mathrm{NH}$ and $\mathrm{SH}$ midlatitudes in the CMIP and AMIP simulations of the $\mathrm{NS}^{-}$models relative to observations. Large excessive downward shortwave radiation occurs in the $\mathrm{SH}$ midlatitudes $\left(30^{\circ}-60^{\circ} \mathrm{S}\right)$ during austral spring and summer due to AMIP cloud biases. The anomalous heating in the extratropics can be spread into the SH tropics by baroclinic eddies (Hwang and Frierson 2013; Kang et al. 2013), causing anomalously high temperatures. As a result, atmospheric asymmetry develops with the 
anomalously excessive (insufficient) precipitation and weakened southeasterly (intensified northeasterly) trade winds in the SH (NH) tropics (Fig. 13c). WES feedback amplifies the coupled biases (Figs. 13c and 13d), corroborating the importance of coupled feedback. In the SH tropics, while the warm SST bias peaks in November-December (the same time as the excessive solar radiation in the $\mathrm{SH}$ midlatitudes), atmospheric biases (precipitation and wind) are most pronounced during January-May when the climatological ITCZ displaces south of the equator (Fig. 13b). This displacement in time of atmospheric biases from the SST bias is probably due to convective feedback that takes place in the climatological ITCZ (Huang et al. 2013).

\section{Summary and discussion}

We have examined the biases in tropical Pacific precipitation pattern in the historical climate simulations of 18 CMIP5 CGCMs together with their AMIP runs. The precipitation deficit in the equatorial Pacific cold tongue (i.e. the cold tongue bias) and excessive precipitation in the SH tropics (i.e. the double ITCZ) remain the most prominent biases for the tropical Pacific climate simulation in the current generation of CGCMs. These two types of biases explain more than three fourths of inter-model variability in tropical Pacific precipitation pattern. Our analysis also shows that the anomalies related to the double ITCZ problem are not confined to the Pacific but rather global in nature.

Based on an inter-model EOF analysis, the first bias mode features precipitation deficit and cool SST biases in the equatorial Pacific cold tongue, along with the easterly wind anomalies in the western half of the equatorial Pacific and too shallow a thermocline in the eastern basin. These anomalies are indicative of Bjerknes feedback. The CMIP-AMIP comparison indicates that the atmospheric biases for the cold tongue bias mode are absent in atmospheric simulations forced with observed SST. These results suggest that the equatorial Pacific cold tongue biases do not come from errors of the atmospheric models but result from the interaction with SST/thermocline via Bjerknes feedback.

Biases of interhemispheric asymmetry in tropical precipitation are of the global scale, and closely linked to anomalous northerly surface winds across the equator in all three ocean basins. From an energetics perspective (e.g. Hwang and Frierson 2013), 
this implies an anomalous northward cross-equatorial energy transport by the Hadley cell, induced by excessive downward solar radiation in the SH midlatitudes. Our analyses suggest a mechanism as follows. The deficient shortwave reflection due to AMIP cloud biases during austral spring and summer warms the SH midlatitudes. The double ITCZ biases develop in the tropics in response to the interhemispheric heating asymmetry. In particular, WES feedback mediates the midlatitude cloud radiative forcing to influence ITCZ. In the SH tropics, despite a November-December peak in warm SST biases, the precipitation and other atmospheric biases are most pronounced during the local rainy season (January-May), indicative of the importance of convective feedback.

In observations, the equatorial Pacific cold tongue is partly tied to the latitudinal asymmetries of the eastern Pacific climatology. Xie (1998) indicates that the offequatorial upwelling induced by the southerly cross-equatorial wind due to the northward-displaced NH ITCZ is crucial for the generation of the equatorial Pacific cold tongue. Previous studies (e.g. de Szoeke and Xie 2008) regard the equatorial Pacific cold tongue biases as a part of the double ITCZ problem. Although the meridional asymmetry biases may be important for the equatorial cold tongue problem in some CGCMs as reported by de Szoeke and Xie (2008), the present study suggests that the equatorial Pacific cold tongue biases are not always tied to the double ITCZ problem, for example, in M4 (a strong equatorial Pacific cold tongue model but with a realistic ITCZ) and M8 (a weak equatorial Pacific cold tongue model but with a strong double ITCZ problem), suggesting that different physical processes are involved for the two types of model biases. In fact, a shallow thermocline bias in oceanic models could cause the Pacific SST to cool and develop the equatorial Pacific cold tongue biases via Bjerknes feedback. In contrast to some previous studies (e.g. Frey et al. 1997; Yu and Mechoso 1999; Luo et al. 2005; Zhang and Song 2010) that emphasize the various atmospheric origins of the equatorial Pacific cold tongue problem, the equatorial Pacific cold tongue biases might originate from ocean models, e.g., a poor ocean mixing scheme. More work is needed to investigate this possibility by analyzing the Oceanic Model Intercomparison Project (OMIP) simulations.

The present study highlights the importance of the SH midlatitude cloud biases in AMIP simulations for triggering the tropical double ITCZ problem. This mechanism 
does not fully explain variations in the degree of the double ITCZ biases among models. It does not rule out other possible sources of error, either. For example, several studies (e.g. Zhang et al. 2007; Chikira 2010) show that the double ITCZ problem of reduced magnitude occurs in some AGCMs forced with prescribed SST.

Acknowledgments. We wish to thank the climate modeling groups (Table 1) for producing and making available their model output, the WCRP's Working Group on Coupled Modeling (WGCM) for organizing the CMIP5 analysis activity, the Program for Climate Model Diagnostics and Intercomparison (PCMDI) for collecting and archiving the CMIP5 multi-model data, and the Office of Science, U.S. Department of Energy for supporting these datasets in partnership with the Global Organization for Earth System Science Portals. This research is supported by the National Basic Research Program of China (2012CB955600), NSF (ATM-0854365), and NOAA. IPRC/SOEST publication \#xx/yy.

\section{REFERENCES}

AchutaRao, K., and K. R. Sperber, 2006: ENSO simulation in coupled oceanatmosphere models: Are the current models better? Climate Dyn., 27, 1-15.

Adler, R. F., and Coauthors, 2003: The version-2 Global Precipitation Climatology Project (GPCP) monthly precipitation analysis (1979-present). J. Hydrometeor., 4, $1147-1167$.

Belluci, A., S. Gualdi, and A. Navarra, 2010: The double-ITCZ syndrome in coupled general circulation models: The role of large-scale vertical circulation regimes. $J$. Climate, 23, 1127-1145.

Bjerknes, J., 1969: Atmospheric teleconnections from the equatorial Pacific. Mon. Wea. Rev., 97, 163-172.

Breugem, W.-P., W. Hazeleger, and R. J. Haarsma, 2006: Multimodel study of tropical Atlantic variability and change. Geophys. Res. Lett., 33, L23706, doi:10.1029/2006GL027831.

Carton, J. A., and B. S. Giese, 2008: A reanalysis of ocean climate using Simple Ocean Data Assimilation (SODA). Mon. Wea. Rev., 136, 2999-3017. 
Chikira, M., 2010: A cumulus parameterization with state-dependent entrainment rate. Part II: Impact on climatology in a general circulation model. J. Atmos. Sci., 67, 2194-2211.

Dai, A. G., 2006: Precipitation characteristics in eighteen coupled climate models. $J$. Climate, 19, 4605-4630.

Davey, M. K., and Coauthors, 2002: STOIC: A study of coupled model climatology and variability in tropical ocean regions. Climate Dyn., 18, 403-420.

de Szoeke, S. P., and S.-P. Xie, 2008: The tropical eastern Pacific seasonal cycle: Assessment of errors and mechanisms in IPCC AR4 coupled ocean-atmosphere general circulation models. J. Climate, 21, 2573-2590.

Donohoe, A., and D. S. Battisti, 2012: What determines meridional heat transport in climate models? J. Climate, 25, 3832-3850.

Du, Y., and S.-P. Xie, 2008: Role of atmospheric adjustments in the tropical Indian Ocean warming during the 20th century in climate models. Geophys. Res. Lett., 35, L08712, doi:10.1029/2008GL033631.

Frey, H., M. Latif, and T. Stockdale, 1997: The coupled GCM ECHO-2. Part I: The tropical Pacific. Mon. Wea. Rev., 125, 703-720.

Guilyardi, E., 2006: El Niño-mean state-seasonal cycle interactions in a multi-model ensemble. Climate Dyn., 26, 329-348.

Ham, Y. G., and J. S. Kug, 2012: How well do current climate models simulate two types of El Niño? Climate Dyn., 39, 383-398.

Hess, P. G., D. S. Battisti, and P. Rasch, 1993: Maintenance of the intertropical convergence zones and the large-scale tropical circulation on a water-covered Earth. J. Atmos. Sci., 50, 691-713.

Hirota, N., Y. N. Takayabu, M. Watanabe, and M. Kimoto, 2011: Precipitation reproducibility over tropical oceans and its relationship to the double ITCZ problem in CMIP3 and MIROC5 climate models. J. Climate, 24, 4859-4873.

Huang, P., S.-P. Xie, K. Hu, G. Huang, and R. Huang, 2013: Patterns of the seasonal response of tropical rainfall to global warming. Nature Geosci., 6, 357-361.

Hwang, Y.-T., and D. M. M. Frierson, 2013: Link between the double-Intertropical Convergence Zone problem and cloud biases over the Southern Ocean. Proc. Natl. Acad. Sci., 110, 4935-4940.

Johnson, N. C., and S.-P. Xie, 2010: Changes in the sea surface temperature threshold for tropical convection. Nature Geosci., 3, 842-845. 
Kalnay, E, and Coauthors, 1996: The NCEP/NCAR 40-year reanalysis project. Bull. Amer. Meteor. Soc., 77, 437-471.

Kang, S. M., D. M. M. Frierson, and I. M. Held, 2009: The tropical response of extratropical thermal forcing in an idealized GCM: The importance of radiative feedbacks and convective parameterization. J. Atmos. Sci., 66, 2812-2827.

Kang, S. M., I. M. Held, and S.-P. Xie, 2013: Contrasting the tropical responses to zonally asymmetric extratropical and tropical thermal forcing. Climate Dyn., doi: 10.1007/s00382-013-1863-0, in press.

Kang, S. M., I. M. Held, D. M. M. Frierson, and M. Zhao, 2008: The response of the ITCZ to extratropical thermal forcing: Idealized slab-ocean experiment with a GCM. J. Climate, 21, 3521-3532.

Latif, M., and Coauthors, 2001: ENSIP: The El Niño simulation intercomparison project. Climate Dyn., 18, 255-276.

Li, G., and S.-P. Xie, 2012: Origins of tropical-wide SST biases in CMIP multi-model ensembles. Geophys. Res. Lett., 39, L22703, doi:10.1029/2012GL053777.

Li, G., B. Ren, C. Yang, and J. Zheng, 2011a: Revisiting the trend of the tropical and subtropical Pacific surface latent heat flux during 1977-2006. J. Geophys. Res., 116, D10115, doi:10.1029/2010JD015444.

Li, G., B. Ren, J. Zheng, and C. Yang, 2011b: Net air-sea surface heat flux during 1984-2004 over the North Pacific and North Atlantic oceans (10 $\left.{ }^{\circ} \mathrm{N}-50 \mathrm{~N}\right)$ : Annual mean climatology and trend. Theor. Appl. Climatol., 104, 387-401.

Lin, J.-L., 2007: The double-ITCZ problem in IPCC AR4 coupled GCMs: Oceanatmosphere feedback analysis. J. Climate, 20, 4497-4525.

Luo, J.-J., S. Masson, E. Roeckner, G. Madec, and T. Yamagata, 2005: Reducing climatology bias in an ocean-atmosphere CGCM with improved coupling physics. J. Climate, 18, 2344-2360.

Ma, J., and S.-P. Xie, 2013: Regional patterns of sea surface temperature change: A source of uncertainty in future projections of precipitation and atmospheric circulation. J. Climate, 26, 2482-2501.

Ma, C.-C., C. R. Mechoso, A. W. Robertson, and A. Arakawa, 1996: Peruvian stratus clouds and the tropical Pacific circulation: A coupled ocean-atmosphere GCM study. J. Climate, 9, 1635-1645.

Mechoso, C. R., cited 2006: Modeling the south eastern Pacific climate: Progress and challenges. NCEP EMC seminar. [Available online at http://www.emc.ncep.noaa. 
gov/seminars/presentations/2006/Mechoso.NCEP.Jan.06.ppt.]

Mechoso, C. R., and Coauthors, 1995: The seasonal cycle over the tropical Pacific in coupled ocean-atmosphere general circulation models. Mon. Wea. Rev., 123, $2825-2838$.

Meehl, G. A., C. Covey, B. McAvaney, M. Latif, and R. J. Stouffer, 2005: Overview of the Coupled Model Intercomparison Project. Bull. Amer. Meteor. Soc., 86, 8993.

Misra, V., L. Marx, M. Fennessey, B. Kirtman, and J. L. Kinter III, 2008: A comparison of climate prediction and simulation over tropical Pacific. J. Climate, 21, 3601-3611.

Philander, S. G. H., D. Gu, D. Halpern, G. Lambert, N.-C. Lau, T. Li, and R. C. Pacanowski, 1996: Why the ITCZ is mostly north of the equator. J. Climate, 9, $2958-2972$.

Randall, D. A., and Coauthors, 2007: Climate models and their evaluation, in Climate Change 2007: The Physical Science Basis, edited by S. Solomon et al., pp. 591648, Cambridge Univ. Press, Cambridge, U. K.

Reynolds, R. W., N. A. Rayner, T. M. Smith, D. C. Stokes, and W. Wang, 2002: An improved in situ and satellite SST analysis for climate. J. Climate, 15, 1609-1625.

Richter, I., and S.-P. Xie, 2008: The muted precipitation increase in global warming simulations: A surface evaporation perspective. J. Geophys. Res., 113, D24118, doi:10.1029/2008JD010561.

Sobel, A. H., and C. S. Bretherton, 2000: Modeling tropical precipitation in a single column. J. Climate, 13, 4378-4392.

Sobel, A. H., I. M. Held, and C. S. Bretherton, 2002: The ENSO signal in tropical tropospheric temperature. J. Climate, 15, 2702-2706.

Song, X., and G. Zhang, 2009: Convection parameterization, tropical Pacific double ITCZ, and upper-ocean biases in the NCAR CCSM3. Part I: Climatology and atmospheric feedback. J. Climate, 22, 4299-4315.

Stephens, G. L., and Coauthors, 2012: An update on Earth's energy balance in light of the latest global observations. Nature Geosci., 5, 691-696.

Taylor, K. E., J. S. Ronald, and G. A. Meehl, 2012: An overview of CMIP5 and the experiment design. Bull. Amer. Meteor. Soc., 93, 485-498.

Trenberth, K. E., J. T. Fasullo, and J. Kiehl, 2009: Earth's global energy budget. Bull. Amer. Meteor. Soc., 90, 311-324. 
Wielicki, B. A., B. R. Barkstrom, E. F. Harrison, R. B. Lee, G. L. Smith, and J. E. Cooper, 1996: Clouds and the Earth's Radiant Energy System (CERES): An Earth Observing System Experiment. Bull. Amer. Meteor. Soc., 77, 853-868.

Wittenberg, A. T., A. Rosati, N.-C. Lau, and J. J. Ploshay, 2006: GFDL's CM2 Global coupled climate models. Part III: Tropical Pacific climate and ENSO. $J$. Climate, 19, 698-722.

Xie, P., and P. A. Arkin, 1997: Global precipitation: A 17-year monthly analysis based on gauge observations, satellite estimates, and numerical model outputs. Bull. Amer. Meteor. Soc., 78, 2539-2558.

Xie, S.-P., 1996: Westward propagation of latitudinal asymmetry in a coupled oceanatmosphere model. J. Atmos. Sci., 53, 3236-3250.

Xie, S.-P., 1998: Ocean-atmosphere interaction in the making of the Walker circulation and equatorial Pacific cold tongue. J. Climate, 11, 189-201.

Xie, S.-P., and S. G. H. Philander, 1994: A coupled ocean-atmosphere model of relevance to the ITCZ in the eastern Pacific. Tellus, 46A, 340-350.

Xie, S.-P., C. Deser, G. A. Vecchi, J. Ma, H. Teng, and A. T. Wittenberg, 2010: Global warming pattern formation: Sea surface temperature and rainfall. $J$. Climate, 23, 966-986.

Yu, J.-Y., and C. R. Mechoso, 1999: Links between annual variations of Peruvian stratocumulus clouds and of SST in the eastern equatorial Pacific. J. Climate, 12, $3305-3318$.

Yu, L., and R. A. Weller, 2007: Objectively analyzed air-sea heat fluxes for the global ice-free oceans (1981-2005). Bull. Amer. Meteor. Soc., 88, 527-539.

Zelinka, M. D., and D. L. Hartmann, 2012: Climate feedbacks and their implications for poleward energy flux changes in a warming climate. J. Climate, 25, 608-624.

Zhang, G. J., and H. Wang, 2006: Toward mitigating the double ITCZ problem in NCAR CCSM3. Geophys. Res. Lett., 33, L06709, doi:10.1029/2005GL025229.

Zhang, G. J., and X. Song, 2010: Convection parameterization, tropical Pacific double ITCZ, and upper-ocean biases in the NCAR CCSM3. Part II: Coupled feedback and the role of ocean heat transport. J. Climate, 23, 800-812.

Zhang, X., W. Lin, and M. Zhang, 2007: Toward understanding the double intertropical convergence zone pathology in coupled ocean-atmosphere general circulation models. J. Geophys. Res., 112, D12102, doi:10.1029/2006JD007878. 
Zheng, Y., J.-L. Lin, and T. Shinoda, 2012: The equatorial Pacific cold tongue simulated by IPCC AR4 coupled GCMs: Upper ocean heat budget and feedback analysis. J. Geophys. Res., 117, C05024, doi:10.1029/2011JC007746.

Zheng, Y., T. Shinoda, J.-L. Lin, and G. N. Kiladis, 2011: Sea surface temperature biases under the stratus cloud deck in the southeast Pacific ocean in 19 IPCC AR4 coupled general circulation models. J. Climate, 24, 4139-4164. 
Table 1. A List of the 18 CMIP5 climate models used in this study and the labels to denote them in the Figures and text.

\begin{tabular}{|c|c|c|}
\hline Model name (label) & Model group (or center) & Including AMIP simulations? \\
\hline CanESM2 (M1) & $\mathrm{CCCma}$ & $\mathrm{N}$ \\
\hline CCSM4 (M2) & NCAR & $\mathrm{N}$ \\
\hline CNRM-CM5 (M3) & CNRM/CERFACS & $\mathrm{Y}$ \\
\hline CSIRO-Mk3.6 (M4) & CSIRO/QCCCE & $\mathrm{Y}$ \\
\hline FGOALS-S2 (M5) & IAP & $\mathrm{Y}$ \\
\hline GFDL-ESM2G (M6) & NOAA GFDL & $\mathrm{N}$ \\
\hline GFDL-ESM2M (M7) & NOAA GFDL & $\mathrm{N}$ \\
\hline GISS-E2-R (M8) & NASA GISS & $\mathrm{Y}$ \\
\hline HadGEM2-CC (M9) & $\mathrm{MOHC}$ & $\mathrm{N}$ \\
\hline HadGEM2-ES (M10) & $\mathrm{MOHC}$ & $\mathrm{N}$ \\
\hline INMCM4 (M11) & INM & $\mathrm{Y}$ \\
\hline IPSL-CM5R-LR (M12) & IPSL & $\mathrm{Y}$ \\
\hline IPSL-CM5R-MR (M13) & IPSL & $\mathrm{N}$ \\
\hline MIROC5 (M14) & JAMSTEC & $\mathrm{Y}$ \\
\hline MPI-ESM-LR (M15) & MPI-M & $\mathrm{Y}$ \\
\hline MPI-ESM-MR (M16) & MPI-M & $\mathrm{Y}$ \\
\hline MRI-CGCM3 (M17) & MRI & $\mathrm{Y}$ \\
\hline NorESM1-M (M18) & $\mathrm{NCC}$ & $\mathrm{Y}$ \\
\hline
\end{tabular}


Table 2. Inter-model correlations between the global and sectoral averaged tropical precipitation asymmetry indices in observations and 18 CMIP5 models. See text for details.

\begin{tabular}{|c|c|c|c|}
\hline & Pacific & South America-Atlantic & Africa-Indian Ocean \\
\hline Global & 0.88 & 0.79 & 0.63 \\
\hline
\end{tabular}

Table 3. Inter-model correlations between the global and sectoral averaged crossequatorial meridional surface winds in observations and CMIP5 models. Note that only 17 CMIP5 CGCMs are employed here since the surface wind data is unavailable in $\mathrm{M} 2$.

\begin{tabular}{|c|c|c|c|}
\hline & Pacific & Atlantic & Indian Ocean \\
\hline Global & 0.92 & 0.82 & 0.79 \\
\hline
\end{tabular}



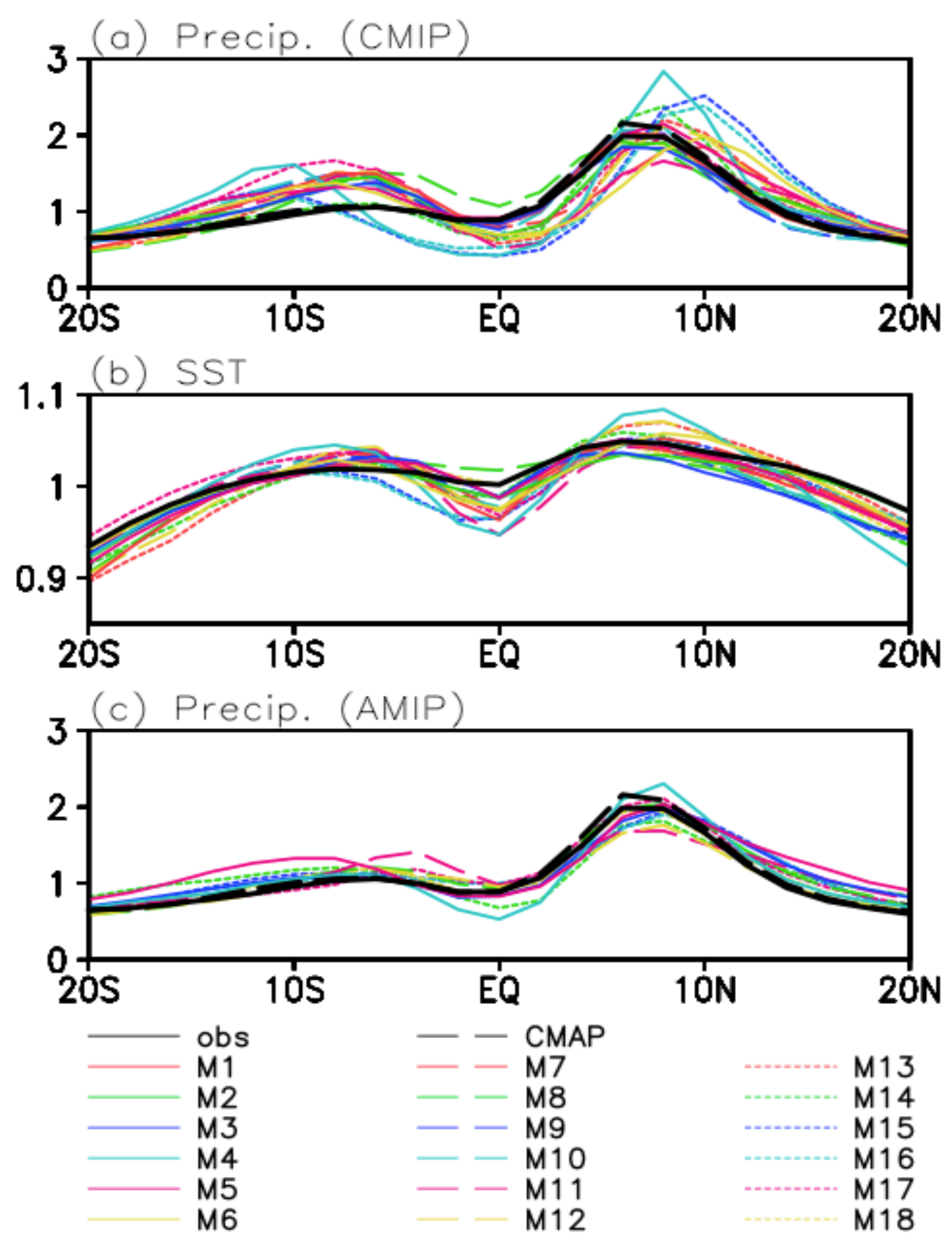

Fig. 1. Zonally and annually averaged (a) precipitation and (b) SST in the tropical Pacific $\left(120^{\circ} \mathrm{E}-80^{\circ} \mathrm{W}\right)$ in observations (black lines) and 18 CMIP5 CGCMs (colored lines); (c) same as in (a), bur for observations and 11 AMIP simulations. Here, the precipitation and SST for observations and each model are normalized by their respective tropical means $\left(20^{\circ} \mathrm{S}-20^{\circ} \mathrm{N}\right)$. 

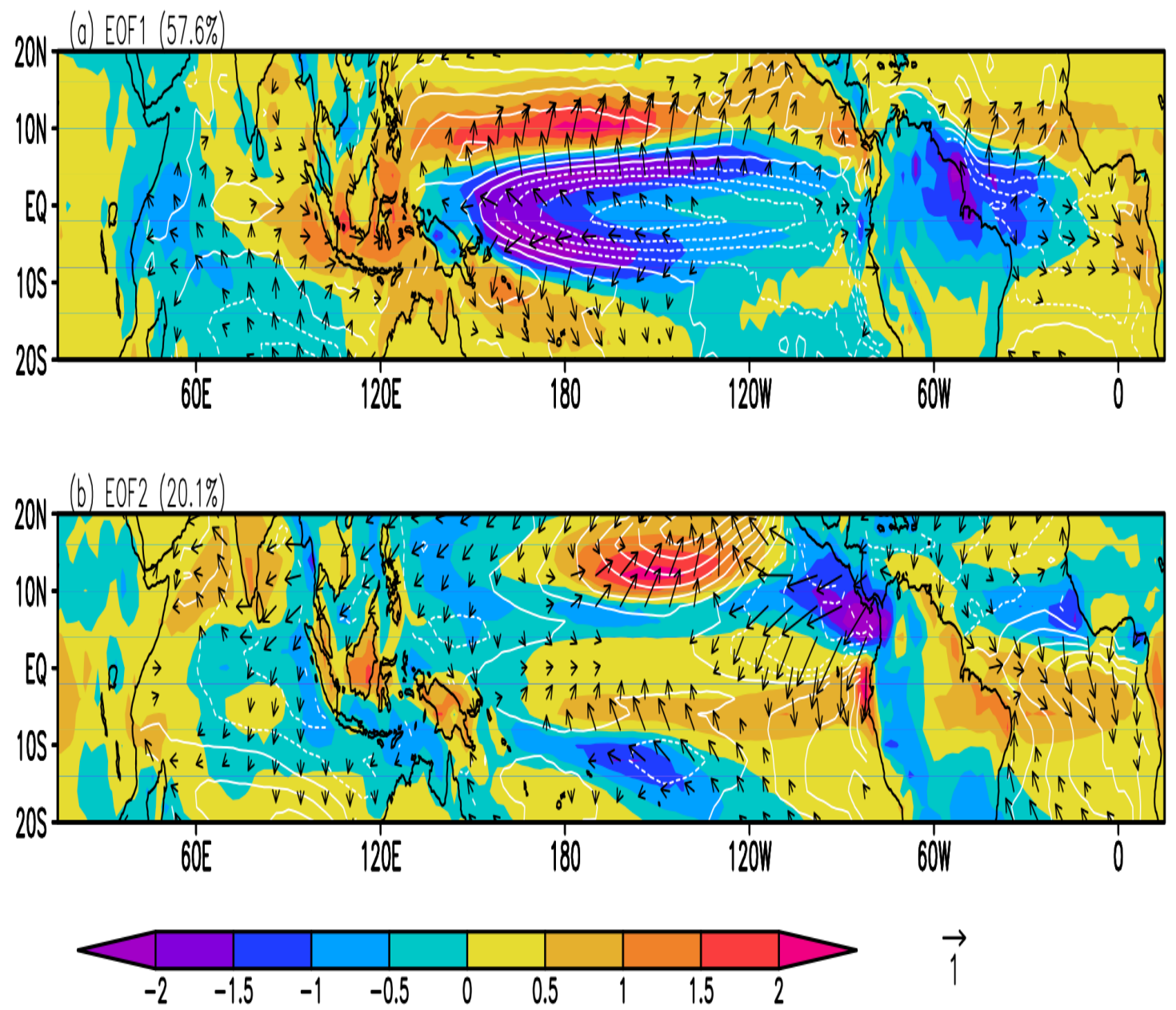

(c) The first leading two PCs

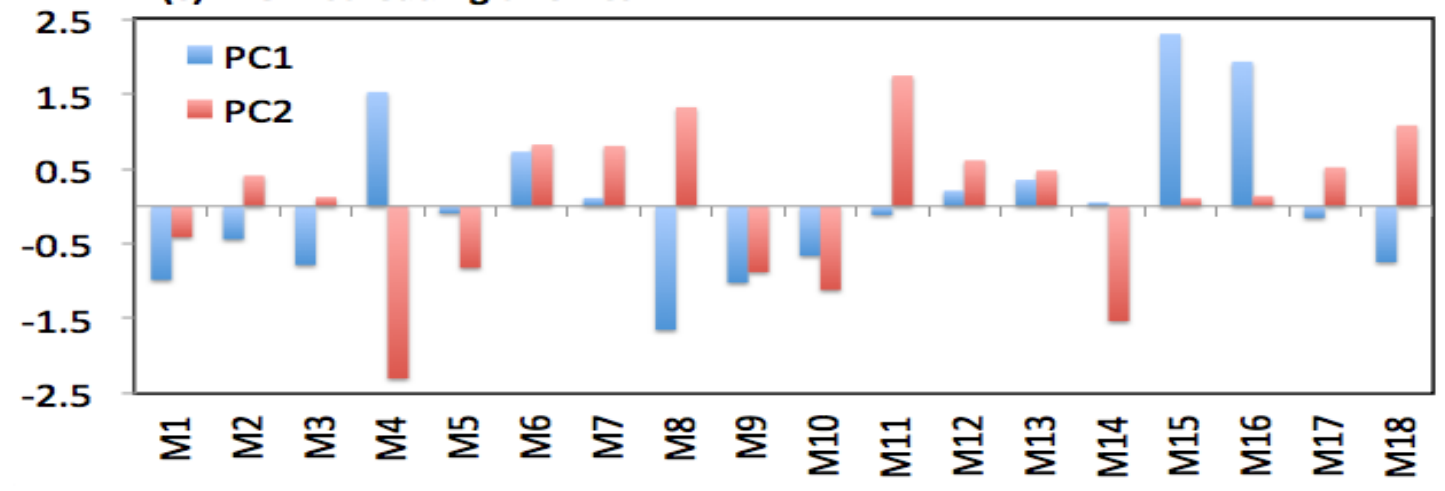

Fig. 2. Regression patterns of normalized precipitation (color shaded), normalized SST (contours), and surface wind velocity (m/s; wind speed smaller than $0.2 \mathrm{~m} / \mathrm{s}$ has been masked out) onto the (a) first and (b) second PCs of inter-model variability in zonally and annually averaged normalized precipitation over the tropical Pacific in 18 CMIP5 CGCMs; (c) the first two PCs. The explained variances are given at the top of (a) and (b). 
(a) Pacific

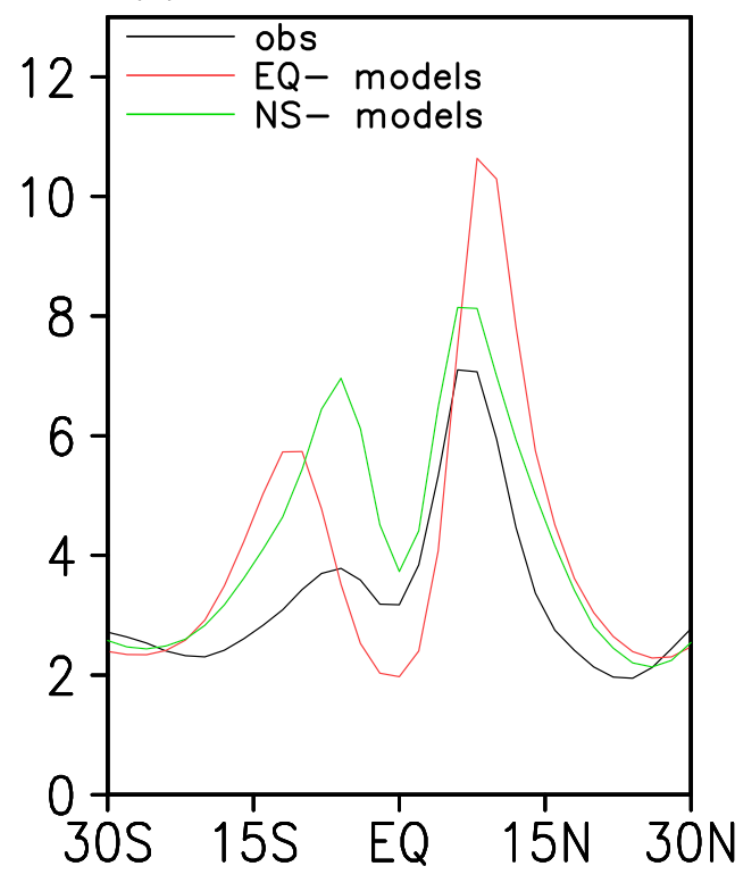

(b) Global

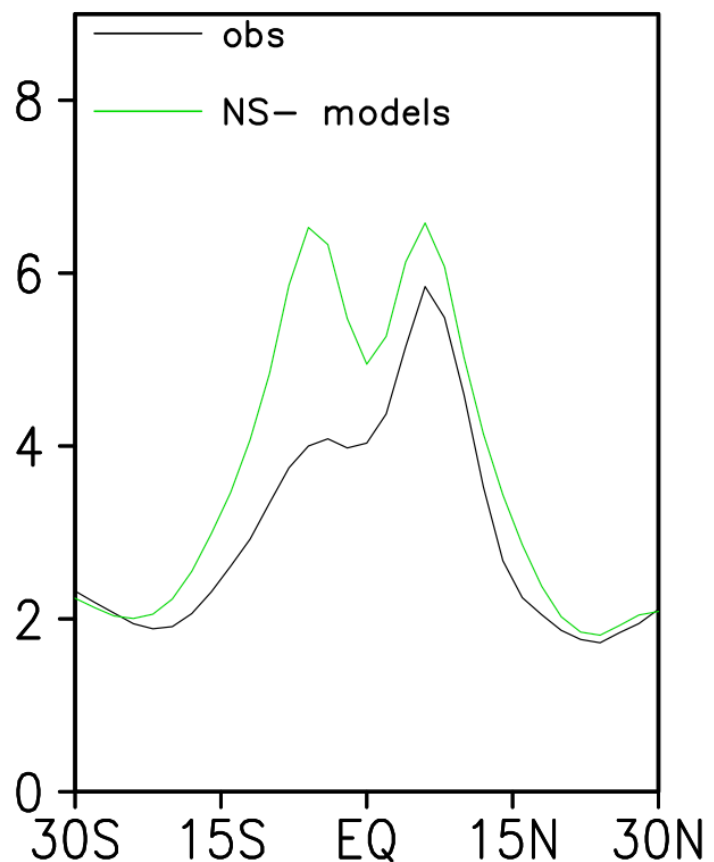

Fig. 3. Zonally averaged precipitation (mm/day) (a) for the tropical Pacific, and (b) for the global tropics in observations, $\mathrm{EQ}^{-}$and $\mathrm{NS}^{-}$climate models. 
(a) Precip. in CMIP vs AMIP

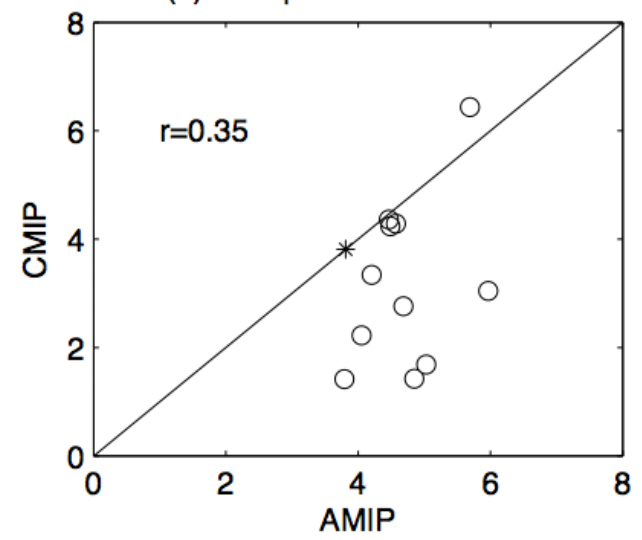

(b) Precip. in CMIP vs CMIP-AMIP

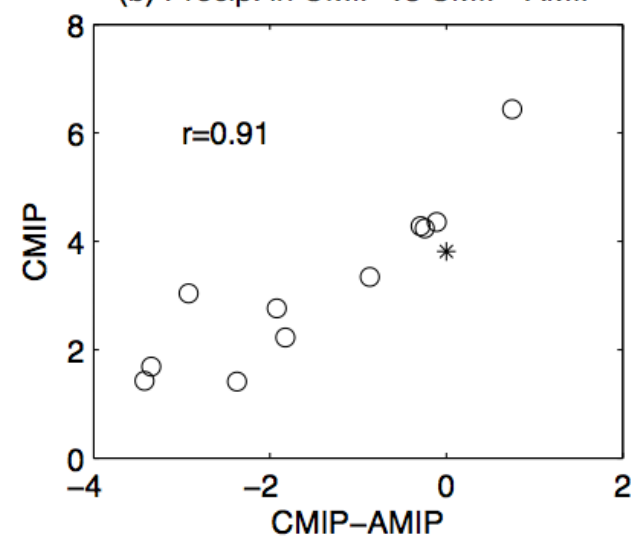

(c) Precip. vs SST in CMIP

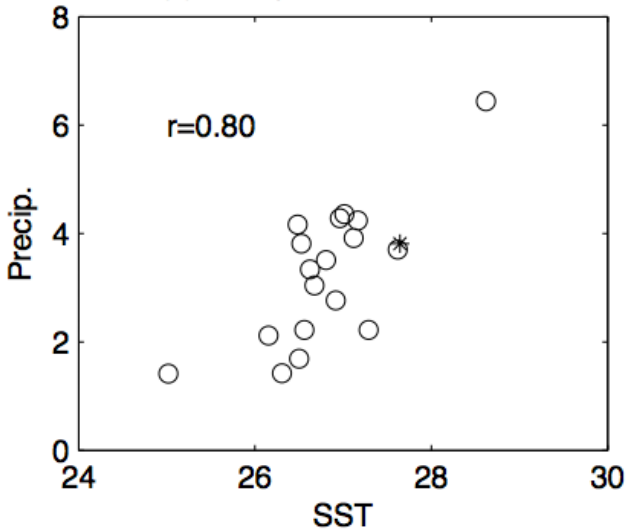

Fig. 4. Comparison of precipitation (mm/day) (a) between CMIP and AMIP; (b) between CMIP and CMIP-AMIP; (c) with SST $\left({ }^{\circ} \mathrm{C}\right)$ in the equatorial Pacific in observations (asterisk) and CMIP5 models (open circles). Note that only a subset of AMIP simulations is available in (a) and (b). 

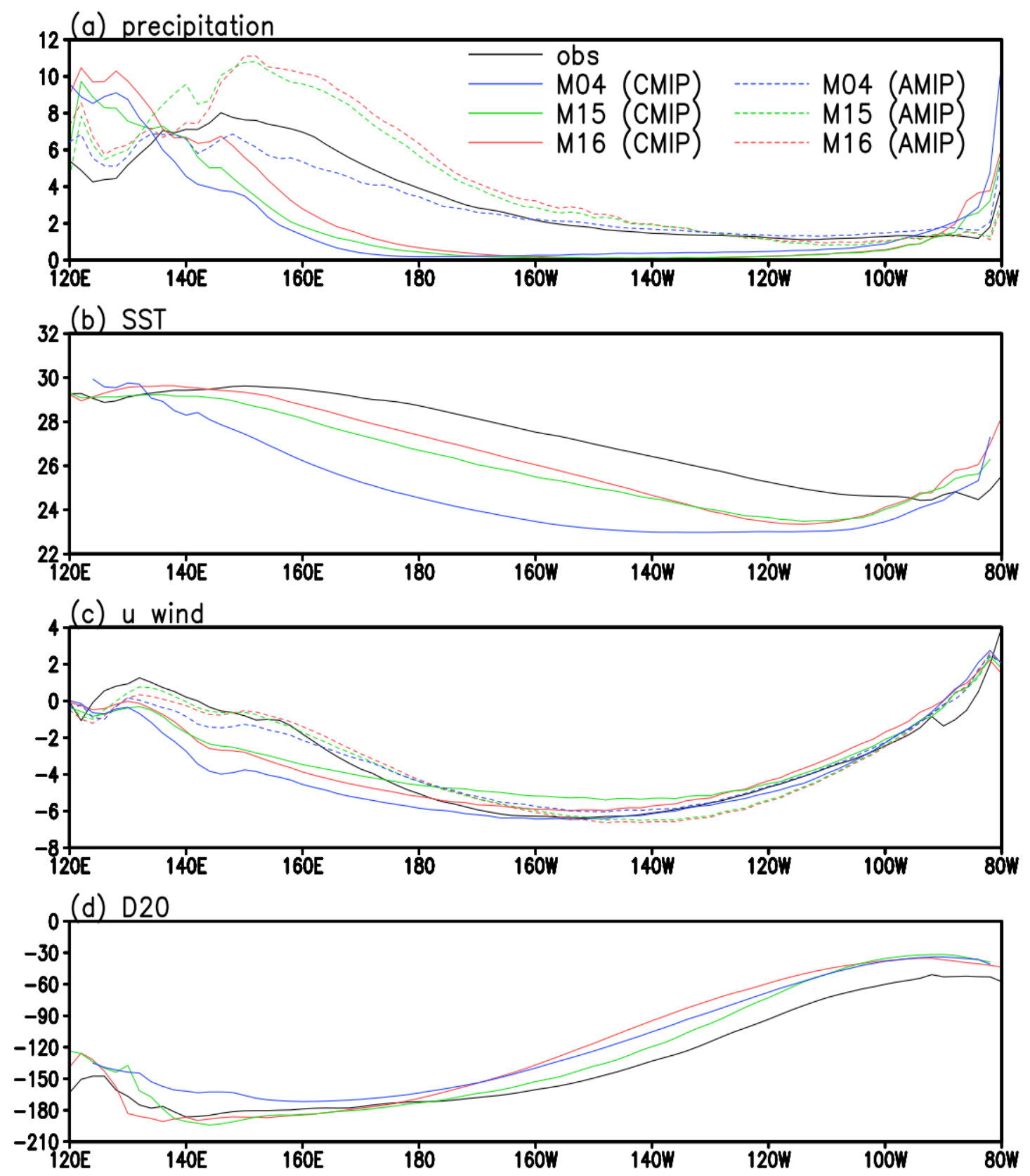

Fig. 5. Zonal sections of (a) precipitation (mm/day), (b) SST $\left({ }^{\circ} \mathrm{C}\right)$, (c) zonal wind $(\mathrm{m} / \mathrm{s})$, and (d) $20^{\circ} \mathrm{C}$ isotherm depth $(\mathrm{m})$ for the Pacific Ocean along the equator $\left( \pm 2^{\circ}\right)$ in observations (black line), the CMIP (solid colored lines) and AMIP (broken colored lines) simulations of the $\mathrm{EQ}^{-}$models. 
(a) V vs PC2

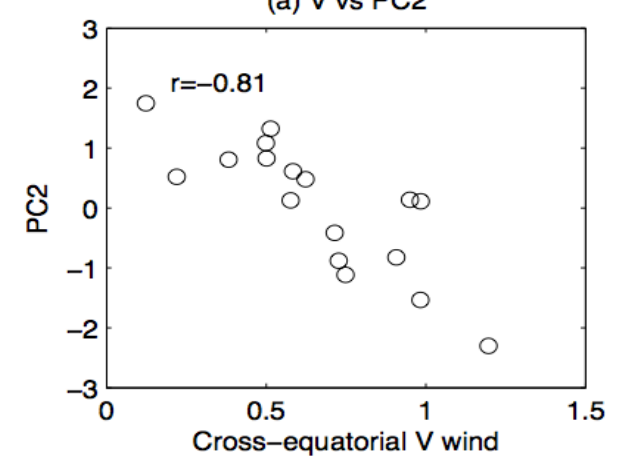

(b) V vs precip. asymmetry

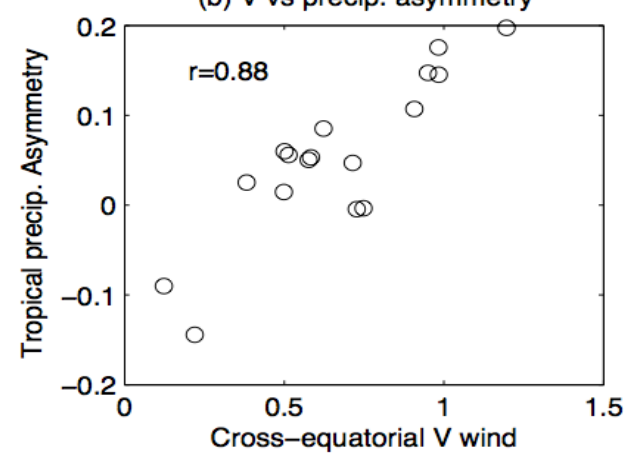

(c) V vs SST asymmetry

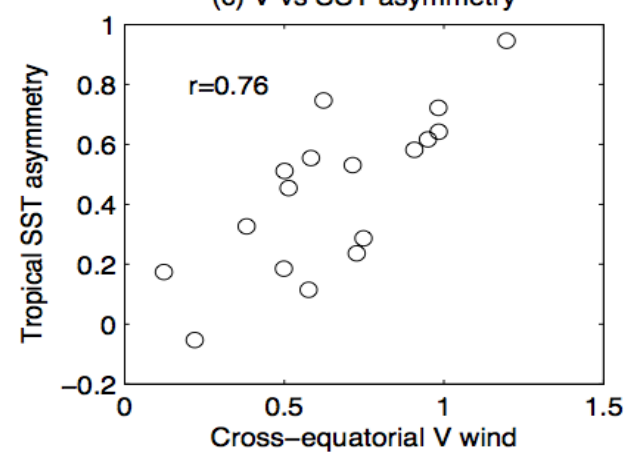

Fig. 6. Globally averaged meridional surface winds $(\mathrm{m} / \mathrm{s})$ on the equator versus (a) the PC2, and the global tropical asymmetry indices $\left(0-20^{\circ} \mathrm{N}\right.$ minus $\left.0-20^{\circ} \mathrm{S}\right)$ in (b) precipitation and (c) SST among CMIP5 CGCMs. Here, the precipitation and SST in each CMIP5 CGCM are normalized by their respective tropical means $\left(20^{\circ} \mathrm{S}-20^{\circ} \mathrm{N}\right)$. Note that only 17 CMIP5 CGCMs are employed here since the surface wind data is unavailable in M2. 

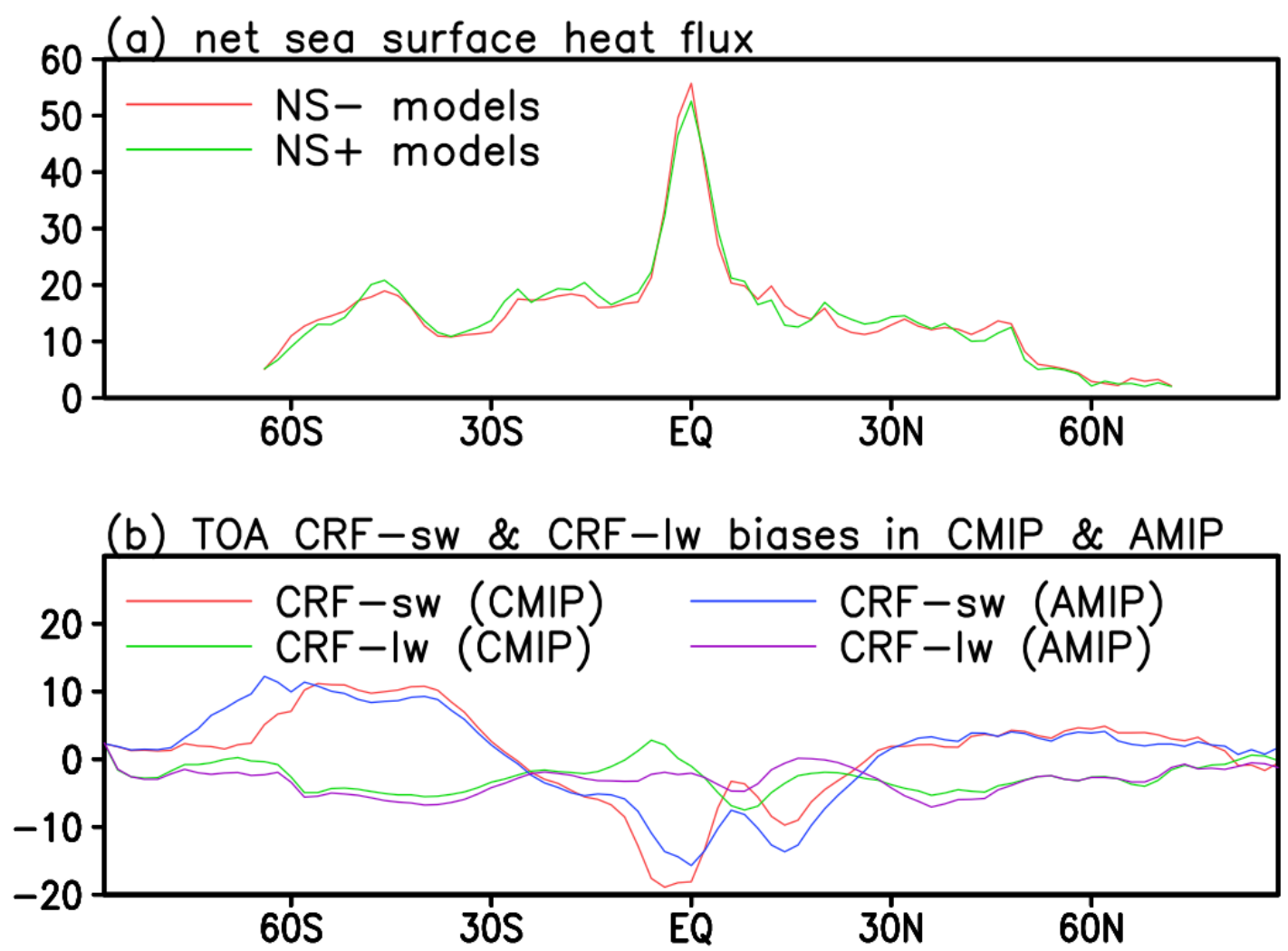

Fig. 7. Zonal mean of (a) net surface heat flux (W/m² and $\mathrm{NS}^{+}$models; (b) biases in TOA CRF-sw and CRF-lw (W/m²; positive: downward) in CMIP and AMIP simulations of the $\mathrm{NS}^{-}$models. 
(a) NH-SH asymmetry
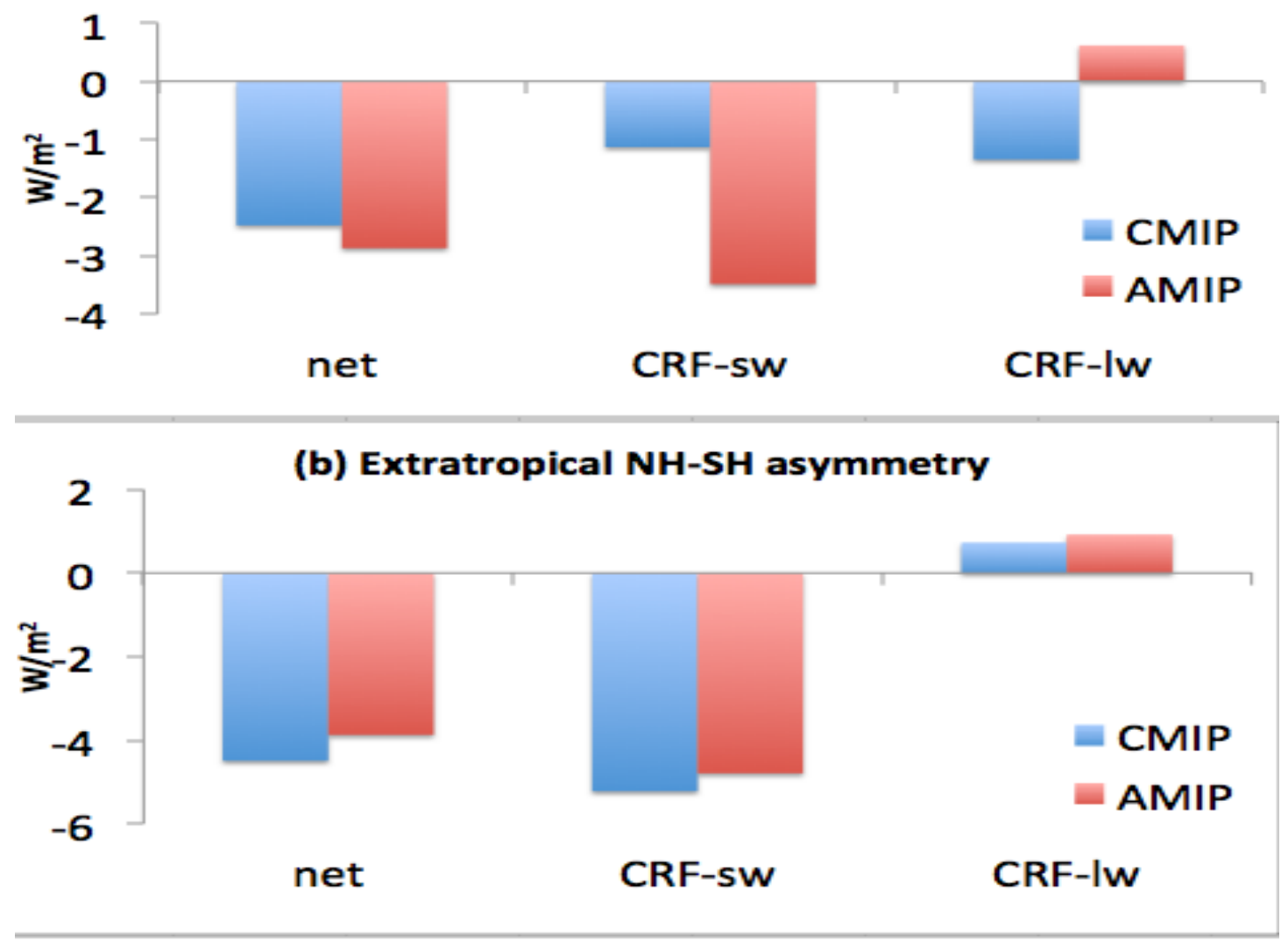

(c) Tropical NH-SH asymmetry

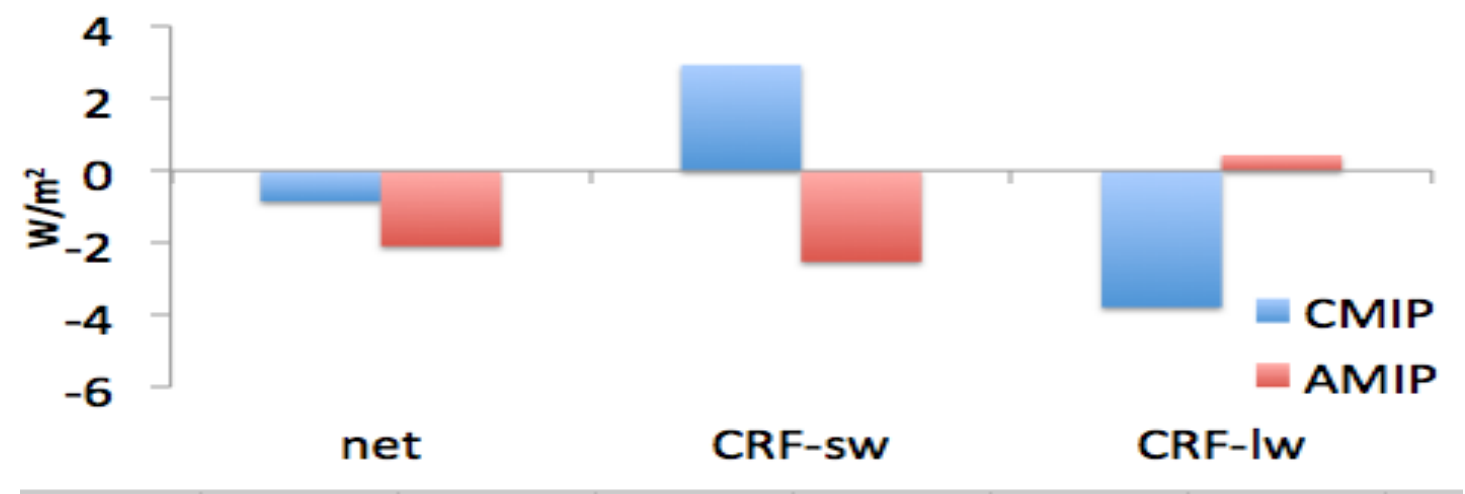

Fig. 8. NH minus SH biases of net downward TOA radiative flux, CRF-sw, and CRF$1 w$ in the CMIP and AMIP runs of the $\mathrm{NS}^{-}$models for (a) the whole hemisphere (0$\left.90^{\circ}\right)$, (b) extratropics $\left(30^{\circ}-60^{\circ}\right)$, and (c) tropics $\left(0-20^{\circ}\right)$. 
(a) Midlatitude CRF-sw vs tropical precip.

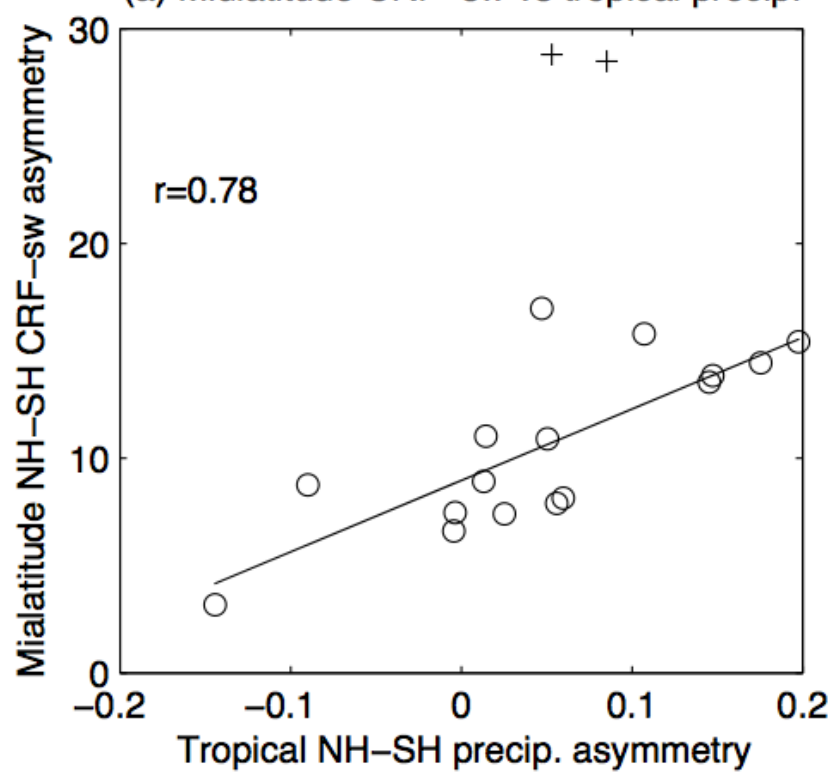

(b) Tropical CRF-Iw vs tropical precip.

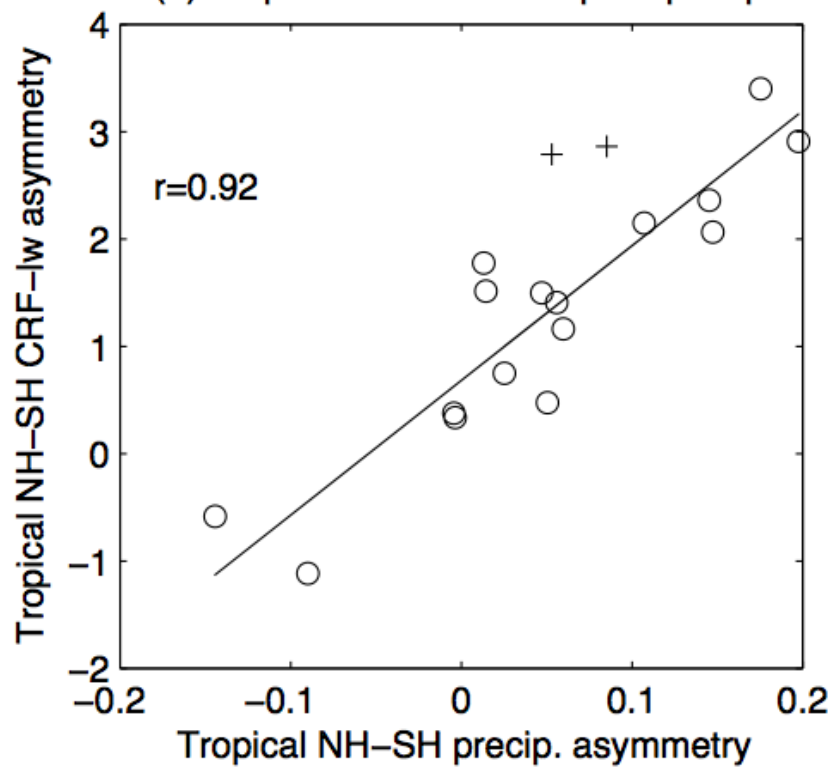

Fig. 9. Comparison of NH-SH difference in normalized tropical precipitation with that in (a) midlatitude CRF-sw $\left(\mathrm{W} / \mathrm{m}^{2}\right)$ and (b) tropical CRF-lw $\left(\mathrm{W} / \mathrm{m}^{2}\right)$ among CMIP5 CGCMs (open circles). Correlation coefficients in (a) and (b) are calculated when excluding IPSL-CM5A-LR (M12) and IPSL-CM5A-MR (M13), models (plus signs) with the large asymmetry biases in net surface heat flux. 

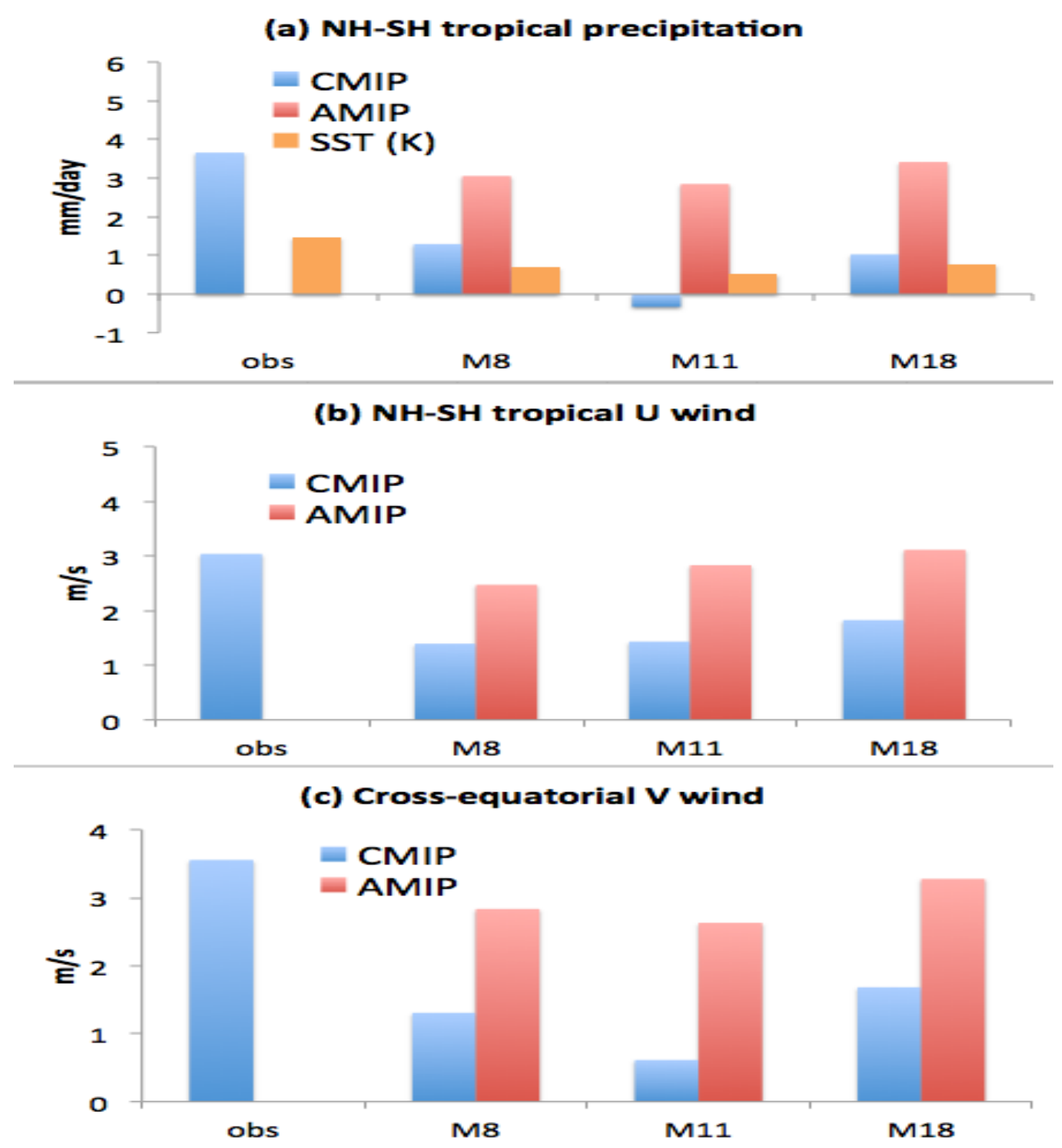

Fig. 10. Area-averaged $\mathrm{NH}\left(0-10^{\circ} \mathrm{N}\right)$ minus $\mathrm{SH}\left(10^{\circ} \mathrm{S}-0\right)$ tropical differences in (a) precipitation/SST and (b) zonal surface wind, and (c) area-averaged cross-equatorial meridional surface wind over the eastern Pacific $\left(140^{\circ} \mathrm{W}-80^{\circ} \mathrm{W}\right)$ and Atlantic $\left(40^{\circ} \mathrm{W}-0\right)$ for observations, and CMIP and AMIP simulations of the $\mathrm{NS}^{-}$models. 
(a) Tropical $\mathrm{NH}-\mathrm{SH}$ precip. asymmetry

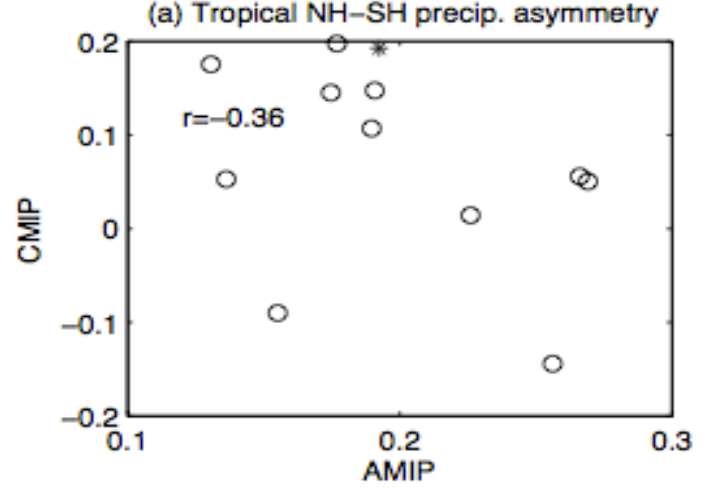

(b) Tropical $\mathrm{NH}-\mathrm{SH}$ precip. asymmetry
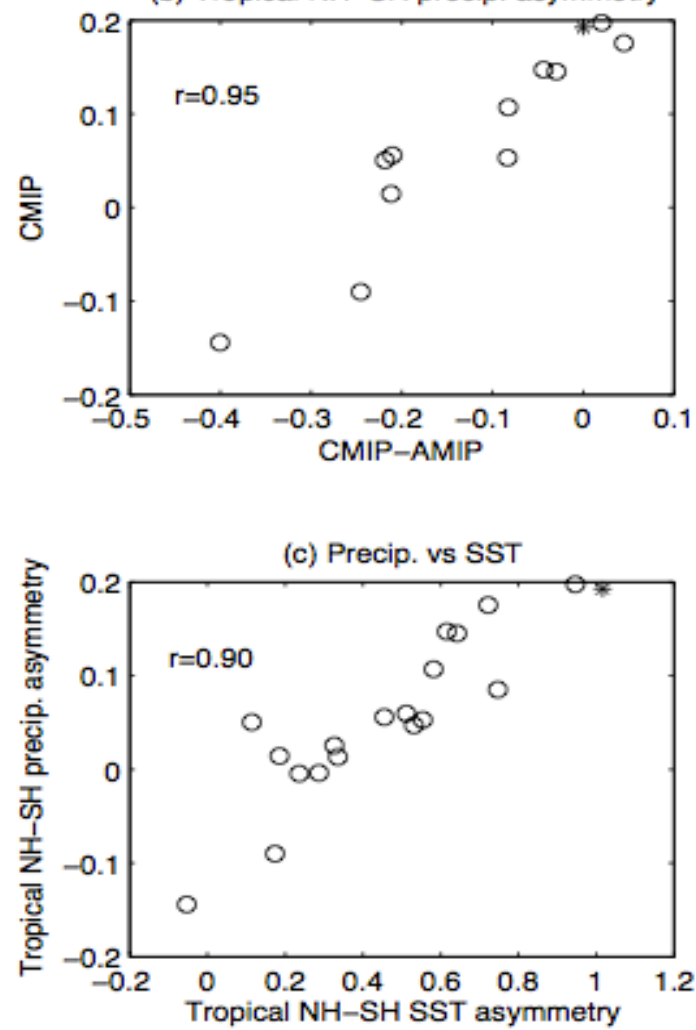

Fig. 11. Comparison of tropical precipitation asymmetry indices (a) between CMIP and AMIP; (b) between CMIP and CMIP-AMIP; (c) with tropical SST asymmetry indices in observations (asterisk) and CMIP5 models (open circles). Note that only a subset of AMIP simulations is available in (a) and (b). 


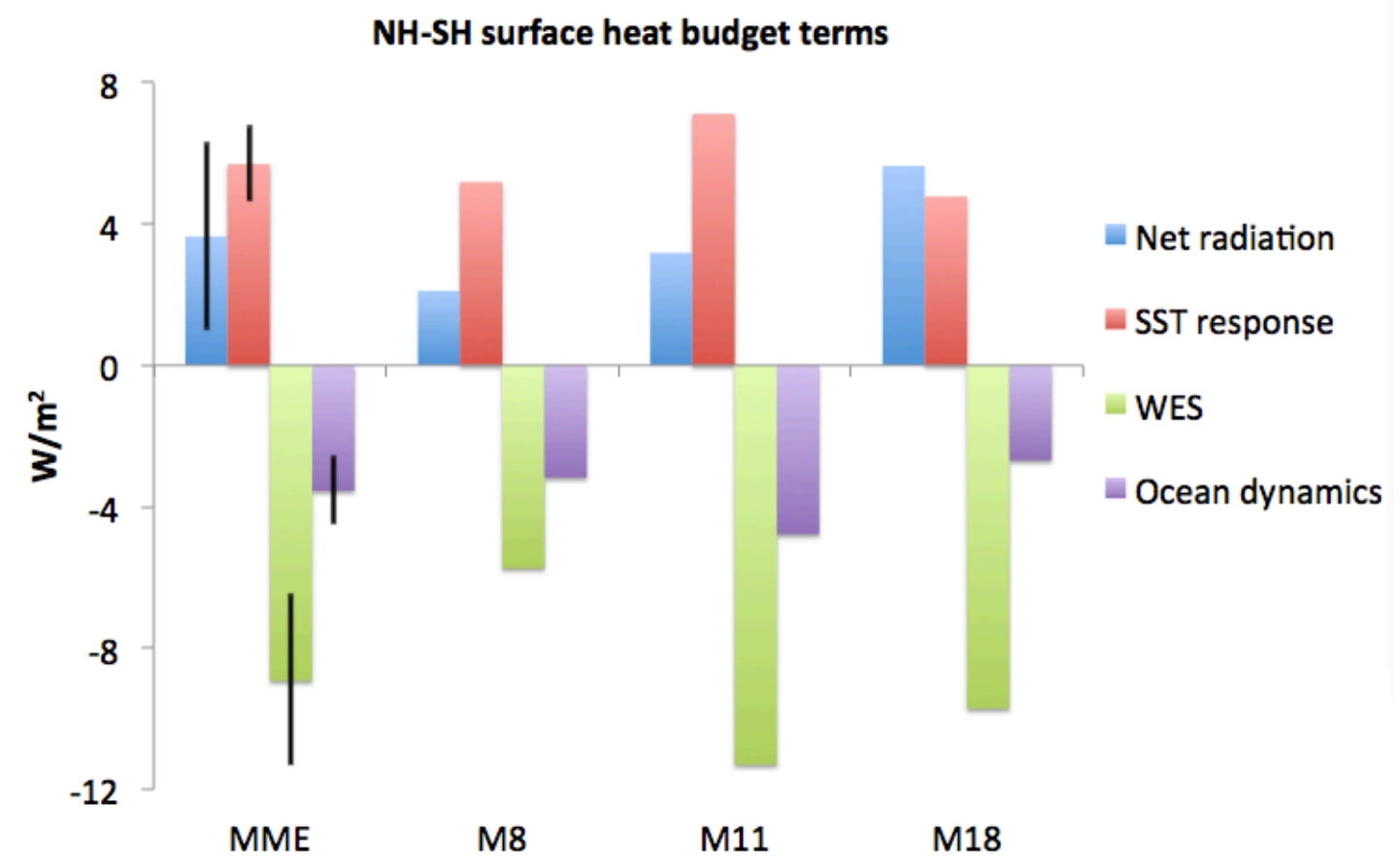

Fig. 12. Area-averaged $\mathrm{NH}\left(0-10^{\circ} \mathrm{N}\right)$ minus $\mathrm{SH}\left(10^{\circ} \mathrm{S}-0\right)$ tropical differences in net surface radiation, SST response and WES terms of surface LHF, and ocean heat transport over the eastern Pacific $\left(140^{\circ} \mathrm{W}-80^{\circ} \mathrm{W}\right)$ and Atlantic $\left(40^{\circ} \mathrm{W}-0\right)$ for ensemble mean (MME) and each of CMIP minus AMIP simulations of the $\mathrm{NS}^{-}$models. Error bars for MME are computed from the standard deviation of the $\mathrm{NS}^{-}$models. Note that the positive (negative) signs on the $\mathrm{Y}$-axis denote a negative (positive) feedback for the NH-SH asymmetry bias in tropical SST. 

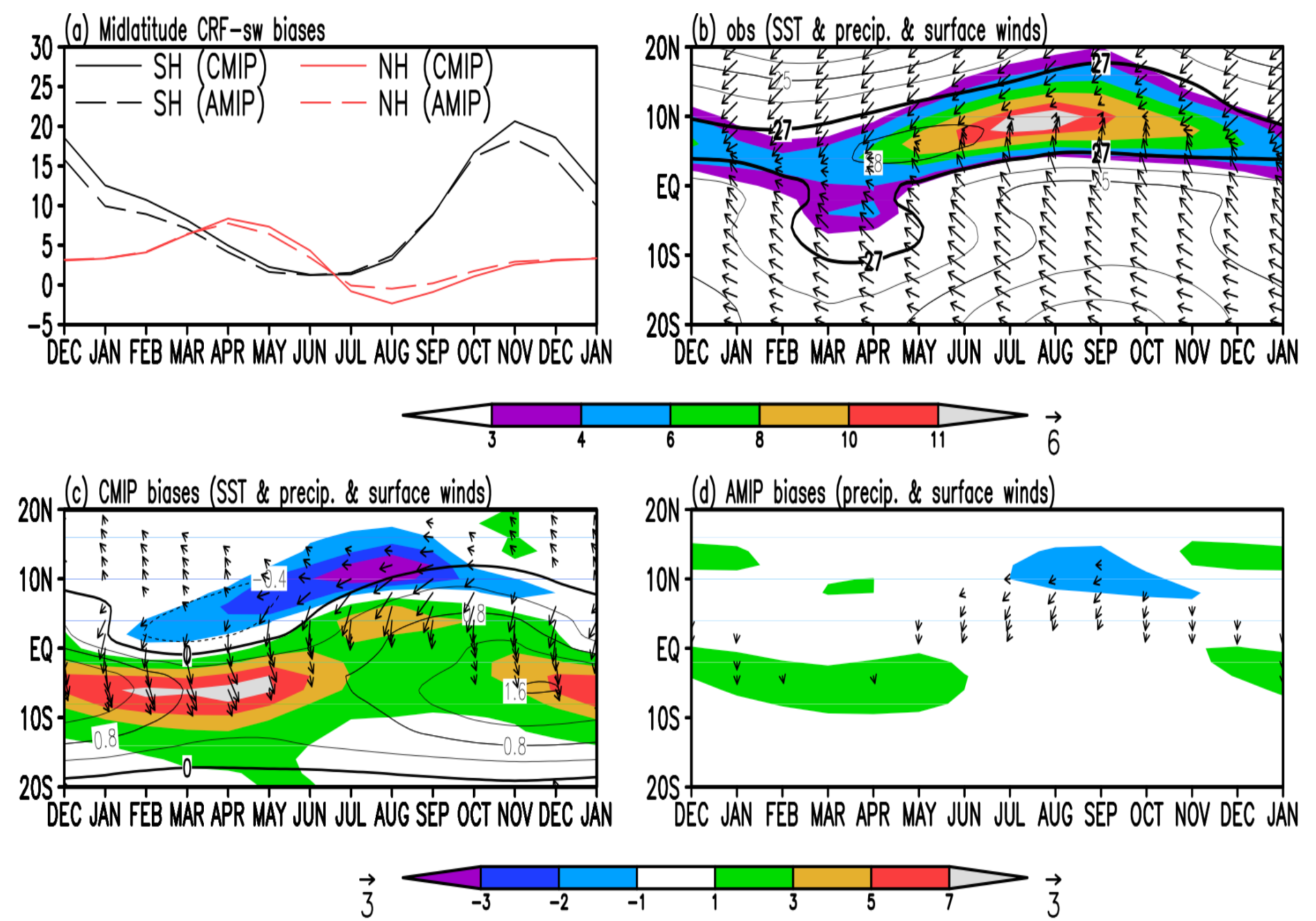

Fig. 13. Seasonal cycle of (a) the CRF-sw $\left(\mathrm{W} / \mathrm{m}^{2}\right)$ biases in the $\mathrm{NH}$ and $\mathrm{SH}$ midlatitudes $\left(30^{\circ}-60^{\circ}\right)$ in CMIP and AMIP simulations of the $\mathrm{NS}^{-}$models. (b) Zonal mean precipitation (color shaded; mm/day), SST (contours; ${ }^{\circ} \mathrm{C}$ ), and surface winds $(\mathrm{m} / \mathrm{s}$; wind speed smaller than $1 \mathrm{~m} / \mathrm{s}$ has been masked out) over the eastern Pacific $\left(140^{\circ}-80^{\circ} \mathrm{W}\right)$ and Atlantic $\left(40^{\circ} \mathrm{W}-0\right)$ for observations; Same as in (b), but for (c) the biases of the $\mathrm{NS}^{-}$models and (d) their AMIP counterparts, respectively. 